\title{
Multi-point geostatistics for ore grade estimation
}

\author{
Yu-Chen Song ${ }^{1}$, Zhan-Ning Liu ${ }^{1}$, Hai-Dong Meng ${ }^{1}$ and Xiao-Yan Yu ${ }^{1}$ \\ ${ }^{1}$ Inner Mongolia University of Science and Technology, Institute of Mining Engineering, Baotou 014010, P.R. China; \\ (songyuchen@imust.edu.cn; 494570031@qq.com; haidongm@imust.edu.cn; 421351047@qq.com)
}

doi: $10.4154 / g c .2019 .23$

Article history:

Manuscript received March 06, 2019 Revised manuscript accepted July 19, 2019 Available online December 20, 2019

Keywords: Training image, Grade, Multi-point geostatistics, Variogram

\begin{abstract}
A multi-point geostatistical method for ore grade estimation is introduced in order to fully utilize existing sampling information. A block model is used to construct a new three-dimensional training image instead of a variogram. Data events and pattern matching is improved, and the directionality of the data template is considered in the matching. The inverse distance weighted method is used to make up for the lack of multi-point geostatistics. The research improves the reliability of multi-point geostatistical estimation. Optimal estimation results for $\mathrm{Li}_{2} \mathrm{O}$ and $\mathrm{Ta}_{2} \mathrm{O}_{5}$ come from the inverse distance weighted, ordinary Kriging, and multi-point geostatistical methods. Multi-point geostatistical estimation results are compared with those of the inverse distance weighted and ordinary Kriging methods. Deviation, trend, and variogram analyses are used to assess the effect of multipoint geostatistical estimation. This study shows that reducing the samples participating in the estimation can reduce the maximum and minimum deviation of the estimated grade to a certain extent. The grade distribution pattern is the primary factor affecting minimum and maximum deviation. This study proves the reliability and accuracy of the multipoint geostatistical method for ore grade estimation.
\end{abstract}

\section{INTRODUCTION}

Ore grade estimation is an important aspect of mine value evaluation. The inverse distance weighted (IDW) and ordinary Kriging $(\mathrm{OK})$ are the most commonly used ore grade interpolation methods (NOVAK ZELENIKA et al., 2017). The IDW method is a widely used simple and convenient ore grade estimation method. The smoothness of IDW interpolation results is directly affected by the number of samples included in the estimation. The OK method is unbiased and has evolved into a series of estimation methods including linear and nonlinear processes. The OK method is one of the most important Kriging methods, giving results with high smoothness (WANG et al., 2016; KUMARI \& SINGH, 2018). In addition, OK uses a variogram to estimate the weight of the samples, but the variogram can only use the information between the two points. Multi-point geostatistics uses a training image instead of a variogram, which considers information from multiple samples, which is advantageous compared to the OK method. The single normal equation simulation (SNESIM) is the most classic multi-point geostatistics (MPG) method. Scholars developed a series of improvements based on the SNESIM method (ZHANG et al., 2015; HANSEN \& LE, 2016). The simulation of patterns (SIMPAT) method compares the similarity between data events and data patterns in the training image and replaces data events with the most similar pattern (BURC ARPAT \& CAERS, 2007; YANG, 2014). The SIMPAT method used the similarity calculation to compare the similarity between the data events and the data patterns in the training image and replaces the data events with the most similar pattern. The SIMPAT method weakened the data stability requirement compared to the SNESIM method, which had some advantages; however, some errors in the data pattern selection and target continuity still exist. For example, sampling results from edge probabilities increase the estimation uncertainty by not considering data fully. A multi-point geostatistical simulation based on the reservoir skeleton (SMPS) used the shape, type, and scale of the target body contained in the skeleton model to constrain and guide the multipoint prediction results of the target simulation (YIN et al., 2008a, 2008b) and was mainly used for river phase mode simulation. Since the skeletal model for the target body was predicted before the simulation, simulation uncertainty can be reduced, and the continuity of the target body can be improved. The FILTERSIM method was used to remedy the long processing time of the SNESIM method (ZHANG et al., 2006). The FILTERSIM method determined the appropriate classification and dimensionality reduction of data events in the image while maintaining estimation accuracy. The dimensionality reduction process was implemented using a mode filter combined with the FILTERSIM method (YU et al., 2016). Mode filters selected for a specific linear combination of mode cell values include directional average, gradient, and curvature. The improved method was primarily used for reservoir phase pattern simulation (WU \& FU, 2016; STRAUBHAAR et al., 2016). Simulations were mostly pattern simulations (VRIES et al., 2009; HUYSMANS et al., 2014), comprehensive simulations (LOU et al., 2015; GARDET et al., 2016), parameter optimization (GAO et al. 2016), and computational efficiency research (ZUO et al., 2016; ABDOLLAHIFARD $\&$ NASIR, 2017). There are few studies on the patterns of continuous variables, and even fewer have been conducted on the calculation of resource reserves using the MPG method.

Here, the SNESIM method is adapted and used for ore grade estimation. Multi-point geostatistics are compared with statistics from the OK and the IDW methods to confirm the validity of the results. Deviation analysis, trend analysis, and variogram analysis are used to examine the estimation characteristics.

\section{RESEARCH METHODS}

This section introduces the IDW, OK, and MPG methods as well as an improved MPG method, which overcomes the uncertainty in matching data templates to data events by incorporating the IDW method. 


\subsection{Inverse distance weighted (IDW) estimation}

The inverse distance weighted (IDW) method is a geometric space interpolation method (spatial statistics) and is one of the most commonly used spatial interpolation methods. It uses the inverse relationship of the distance index powers of known neighbour values to estimate grid point values and can be expressed by the equation (LI et al., 2008):

$$
Z=\frac{\sum_{i=1}^{n} \frac{1}{d_{i}^{P}} Z_{i}}{\sum_{i=1}^{n} \frac{1}{d_{i}^{P}}}
$$

where $Z$ is the estimation value for the point to be estimated. $Z_{i}$ is the $i$-th $(i=1,2, \ldots, n)$ sample participating in the estimation. $d_{i}$ is the distance between the point to be estimated and the sample. $P$ is the power of the distance. The value of $P$ significantly affects the interpolation result, and its selection criterion is the minimum average absolute error.

\subsection{Kriging estimation}

It is important to understand the theoretical explanation of the ordinary Kriging method, its experimental variogram, and theoretical variogram.

\subsubsection{Variogram}

The variogram is an important tool in the OK method and can be used alone or as the basis for the Kriging method to study the spatial variability of ore grades. The experimental variogram can be written as:

$$
\gamma(x, h)=\frac{1}{2} E[Z(x)-Z(x+h)]^{2}
$$

where $\gamma(x, h)$ is the variogram value. $h$ is the lag distance or distance between samples. $Z(x)$ and $Z(x+h)$ are the observed values of the regionalized variable $Z$ at positions $x$ and $x+h$, respectively.

The experimental variogram provides the spatial variation of the sample grade. However, an experimental variogram cannot be directly used in Kriging estimation (GEIGER et al., 2016). It is necessary to fit the experimental variogram and obtain a theoretical curve after fitting, which is the theoretical variogram. The theoretical variogram can be used in Kriging estimation, and theoretical variograms used in this study are based on spherical, power function, and fractal models.

\section{Spherical model}

$$
\gamma(h)= \begin{cases}0 & h=0 \\ C_{0}+C\left(\frac{3}{2} \cdot \frac{h}{a}-\frac{1}{2} \cdot \frac{h^{3}}{a^{3}}\right) & 0<a \leq h \\ C_{0}+\mathrm{C} & h>a\end{cases}
$$

where $\gamma(h)$ is the value of experimental variogram. $C_{0}$ is the nugget value. $h$ is the lag distance. $C$ is the arch height. $C_{0}+C$ is the sill value. $a$ is the range.

\section{Power function mode}

$$
\gamma(h)=A h^{\theta}, \quad 0<\theta<2
$$

where $\theta$ is a power exponent. $A$ is a constant. Other parameters are the same as Eq. (3).

\section{Fractal model}

The variogram of the fractal Brownian motion is expressed as:

$$
\gamma(h)=V_{H} h^{2 H}
$$

where: $V_{H}$ is a constant. $h$ is the lag distance. $H$ is the discontinuity index (Hurst index).

\subsubsection{Ordinary Kriging (OK) estimation}

If $x$ be any point to be evaluated in the study area, then the ore grade at point $x$ can be expressed as:

$$
Z_{V}{ }^{*}(x)=\sum_{i=1}^{n} \lambda_{i} Z\left(x_{i}\right)
$$

where $Z_{V}^{*}(x)$ is an estimation value of the point to be estimated. $x_{i}$ is the $i$-th most recent sample around the point to be estimated. $Z\left(x_{i}\right)$ is the grade of the $i$-th most recent sample within the range to be estimated. $\lambda_{i}$ is the weight.

In Eq. (6), the estimation depends on the weight coefficient $\lambda_{i}$, while solving for the optimal $\lambda_{i}$ value becomes essential to estimation. The best estimation is considered to be unbiased and has the least variance (optimal condition) in the OK. If the $E[Z(x)]=m$ of the ore grade $Z(x)$ is known, the calculation is called a simple Kriging estimation. If $E[Z(x)]$ of $Z\left(x_{i}\right)$ is unknown, the calculation is called ordinary Kriging $(\mathrm{OK})$.

\subsection{Multi-point geostatistical estimation \\ 2.3.1. Principle of the SNESIM}

The classic SNESIM method takes multi-point geostatistics from theory to practicality, which is of great significance (STREBELLE, 2017). The SNESIM uses data events to estimate the local probability of the point to be estimated. For two-point statistics, the probability that the variable type is $s_{k}$ state is written as:

$$
\Phi(h, k)=E[I(u ; k) \times I(u+h ; k)]
$$

where $\Phi(h, k)$ represents the probability that variable types are $s_{k}$ states at locations $u$ and $u+h$. $s_{k}$ represents the possible $k$ states of the attribute $\mathrm{S} . k=1, \ldots, K . h$ is the distance between two points. $I(u ; k)$ represents the probability when the state at position $u$ is $s_{k}$. $I(u+h ; k)$ represents the probability when the state at position $u+h$ is $s_{k}$.

The sample $t_{n}$ is determined by $n$ vectors $\left(h_{\alpha}, \alpha=1, \ldots, n\right)$. The probability that $n$ data points $\left(u+h_{1}, \ldots, u+h_{n}\right)$ are simultaneously $s_{k}$ can be expressed by the following equation:

$$
\Phi(h, k)=E\left[\prod_{\alpha=1}^{n} I\left(u+h_{\alpha} ; k\right)\right]
$$

where $\Phi(h, k)$ represents the probability that multiple point attributes are $s_{k}$.

$\left(u+h_{1}, \ldots, u+h_{n}\right)$ take the values of the probability of $s_{k l}, \ldots, s_{k n}$ respectively, which is written as:

$$
\Phi\left(h_{1}, \cdots, h_{n}, k_{1}, \cdots, k_{n}\right)=E\left[\prod_{\alpha=1}^{n} I\left(u+h_{\alpha} ; k_{\alpha}\right)\right]
$$

where $\Phi\left(h_{1}, \ldots, h_{n}, k_{1}, \ldots, k_{\mathrm{n}}\right)$ is the probability that multiple points have different attribute states.

By analyzing the definition of a data event, the probability of the data event $d_{n}$ is the probability of the above probability event, which is written as:

$$
\Phi\left(h_{1}, \cdots, h_{n}, k_{1}, \cdots, k_{n}\right)=\frac{c\left(d_{n}\right)}{N_{n}}
$$


where $c\left(d_{n}\right)$ is the number of times the data event $d_{n}$ appears in the training image. $N_{n}$ is the number of data events contained in the training image.

Assuming that the data event constitutes the indicator variable, $D$ is written as:

$$
D= \begin{cases}1 & S\left(u_{\alpha}\right)=s_{k \alpha}, \quad \forall \alpha=1, \cdots, n \\ 0 & \text { Other }\end{cases}
$$

where $S\left(u_{\alpha}\right)=s_{k \alpha}$, which indicates a case where the attribute $S$ is the state $k$ at location $u_{\alpha}$.

The value of the estimation center point $A_{k}$ can be written as:

$$
A_{k}= \begin{cases}1 & S(u)=s_{k} \\ 0 & \text { Other }\end{cases}
$$

where $A_{k}$ is an indicator variable associated with the occurrence of state $s_{k}$ at location $u$.

Using the simple Kriging method, the probability that any point will have a given attribute type is written as:

$$
\operatorname{Prob}\left[A_{k}=1 \mid D=1\right]=E\left[A_{k}\right]+\lambda(1-E[D])
$$

where $A_{k}=1$ is an indicator value corresponding to datum value $s_{k}$ at location $u . D=1$ is the observed data event. $E\left[A_{k}\right]$ is the probability of the (unknown) state at location $u$ to be $s_{k}$. $E[\mathrm{D}]$ is the probability of the conditioning data event occurring. $\lambda$ is the single weight.

The weight $\lambda$ can be determined by:

$$
\begin{gathered}
\lambda \operatorname{Var}[D]=\operatorname{Cov}\left[A_{k}, D\right], \text { and } \\
\operatorname{Cov}\left[A_{k}, D\right]=E\left[A_{k} D\right]-E\left[A_{k}\right] E[D], \\
\operatorname{Var}[D]=E[D](1-E[D]) .
\end{gathered}
$$

Thus there is:

$$
\lambda=\frac{E\left[A_{k} D\right]-E\left[A_{k}\right] E[D]}{E[D](1-E[D])}
$$

Then there is:

$$
\begin{aligned}
\operatorname{Prob}\left[A_{k}=1 \mid D=1\right]= & E\left[A_{k}\right]+(1-E[D]) \\
& =E\left[A_{k}\right]+\frac{E\left[A_{k} D\right]-E\left[A_{k}\right] E[D]}{E[D]} \\
& =\frac{E\left[A_{k} D\right]}{E[D]}=\frac{\operatorname{Prob}\left[A_{k}=1, D=1\right]}{\operatorname{Prob}[D=1]}
\end{aligned}
$$

With the single normal equation described in Eq. (15), the conditional probability of the point attribute state $s_{k}$ can be calculated. The attribute state value is obtained by the quotient of

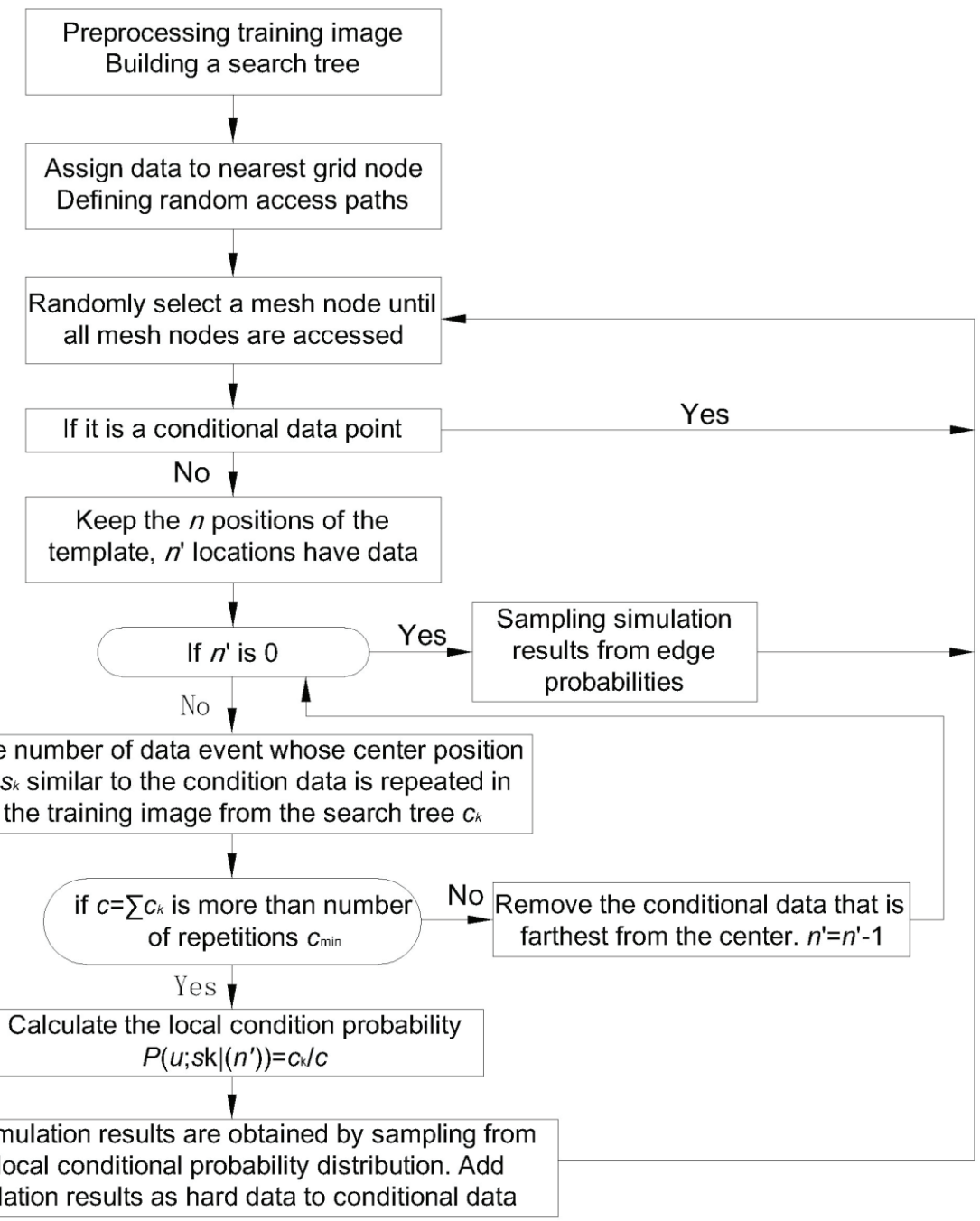


two multi-point probabilities, which are crucial to obtaining the conditional probability. Therefore, the probability of $\operatorname{Prob}[D=1]$ can be obtained by calculating the number of repetitions of $D$ in the training image.

$$
\operatorname{Prob}[D=1]=\Phi\left(h_{1}, \cdots, h_{n}, k_{1}, \cdots, k_{n}\right)=c\left(d_{n}\right) / N_{n} \text { issimi- }
$$

lar to the derivation of $D$ probability. $\operatorname{Prob}\left[A_{k}=1, D=1\right]$ can also be obtained by calculating the repetitions of $A_{k}=1$ and $D=1$ in the training image:

$$
\operatorname{Prob}\left[A_{k}=1, D=1\right] \approx \frac{c_{k}\left(d_{n}\right)}{N_{n}}
$$

where $c_{k}\left(d_{n}\right)$ represents the number of times the data event is at the centre position, whose attribute is $s_{k}$, and is repeated in the training image. From the calculation of $c\left(d_{n}\right)$ and $c_{k}\left(d_{n}\right)$, the probability can be obtained from the search tree. Therefore, the MPG method can be used to estimate the point value.

The conditional probability distribution of the data event at the point to be estimated is extracted from the search tree before the estimation is performed at location $u$, and the local conditional probability is calculated for this location. The conditional probability distribution function at the point to be estimated is obtained. If the conditional probability at the point to be estimated is 0 , the global probability is extracted, instead of the local conditional probability. If the data event at the point to be estimated rarely appears in the training image, the data point (sample grade point) furthest from the point to be estimated is removed, the number of data events repetitions at the point to be evaluated is increased, and the reliability of the local probability estimation is improved.

\subsubsection{SNESIM improvement}

In order to achieve accurate ore grade estimation, sample grade values need to be discretized in to multiple intervals. The number of discrete intervals influences estimation accuracy. The training image replaces the variogram in the multi-point geostatistical analysis. Training images used in the precious stratified phase model simulation are not suitable for ore grade estimation. Therefore, it is important to build a new training image for ore grade estimation.

\section{Sample processing}

Ore grade value is a continuous variable and can be discretized using the following expression:

$$
p_{k}=r p\left[\frac{p-p_{\min }}{p_{\max }-p_{\min }} \times N\right]
$$

where $p$ is an arbitrary grade value. $p_{\max }$ is the maximum value of the samples. $p_{\min }$ is the minimum value of the samples. $r p$ indicates an integer up. $N$ is the number of discrete intervals. $p_{k}$ is the discretized grade value.

In the estimation, the attribute $(S)$ is divided into $k$ states, where $k$ is equivalent to the number $(N)$ of discrete intervals. The estimation result of continuous variables is still a continuous variable. The probability that the attribute to be evaluated is $S_{k}$ is $c_{k}\left(d_{n}\right) / c\left(d_{n}\right)$ in MPG. The authors use the combined weighting values of $S_{1}, S_{2}, \ldots, S_{k}, \ldots, S_{n}$, and perform inverse discretized processing on the value of the estimated attribute with probability values used as the weights. This process can be expressed as:

$$
p_{E}=\frac{\sum_{k=1}^{N} \mathrm{c}_{\mathrm{k}}\left(d_{n}\right) \times p_{k}}{c\left(d_{n}\right) \times N} \times\left(p_{\max }-p_{\min }\right)+p_{\min }-\frac{p_{\max }-p_{\min }}{2 \times N}
$$

where $p_{E}$ is an estimation grade. $N$ is the number of possible values of the estimation point, which is the same as the number of discrete intervals. $p_{k}$ is the grade value that may be obtained.

In theory, more discrete intervals lead to more accurate estimates. In fact, too many discrete intervals will reduce the matching rate between data events and data patterns, which reduces estimation accuracy. Multiple discrete interval schemes are used to evaluate the estimated effects and select the optimal estimates in subsequent studies.

\section{Directional problems and improvements in data event matching}

The data template shown in Fig. 2. is used in multi-point geostatistical estimation. According to the SNESIM method, the estimation works by matching the six samples closest to the point to be estimated with six ore grade data (data pattern) obtained from scanning the training image; however, $u_{1}, u_{2}, \ldots, u_{6}$ are directional in the data template (Fig. 2), and it is not appropriate to only consider the 6 closest points to match the data pattern. Therefore, the authors consider the directional characteristics of the data event and samples. The estimation searches for more surrounding data, matches the data event direction with the template direction, and discards the samples with poor matching in some directions. The data template uses six data points corresponding to the six directions, which are the positive and negative directions of $\mathrm{X}, \mathrm{Y}$, and $Z$, respectively. $(1,0,0),(-1,0,0),(0,1,0),(0,-1,0),(0,0,1)$, and $(0,0,-1)$ indicate the 6 directions in the template. The vector $h_{\alpha}$ $(\alpha=1, \ldots, n)$ is used to indicate the directionality of the data. The six data points from the $n$ dataset that best match the six directions in the template are selected for the estimation. Matching a single data with one direction of the template is written as:

$$
\operatorname{corr}[h, l]=\frac{\sum_{j=1}^{3}\left(h_{j}-\bar{h}\right)\left(l_{j}-\bar{l}\right)}{\sqrt{\sum_{j=1}^{3}\left(h_{j}-\bar{h}\right)^{2}} \sqrt{\sum_{j=1}^{3}\left(h_{j}-\bar{l}\right)^{2}}}
$$

where corr $[h, l]$ represents the relationship coefficient between data events and the data template in a certain direction. $h_{j}$ and $l_{j}$ indicate the three-dimensional coordinates of the data points in the data event and data template, respectively. $\bar{h}$ and $\bar{l}$ are the average values of $h_{j}$ and $l_{j}$.

\section{Data template and training image}

Previous studies concerning the influence of the data template size on estimation results have shown that large data templates do not significantly contribute to improving the estimation accuracy (HU \& CHUGUNOVA, 2008). Therefore, a small data template is used in this study to save computing time (Fig. 2). The data template is used to scan the training image of porcelain clay to obtain the corresponding data pattern and store it in the search tree. According to the SNESIM method, the estimation principle is shown in Fig. 1. Local conditional probabilities are obtained by matching data events and data patterns. Monte Carlo sampling is then used to determine the point value to be estimated. Points for which the conditional probability distribution cannot be obtained by matching, are estimated from the global probability using the Monte Carlo sampling method. In practice, the number of data events that do not get a conditional probability by matching with the model is relatively small. In this case, using the global probability instead of the local conditional probability is 


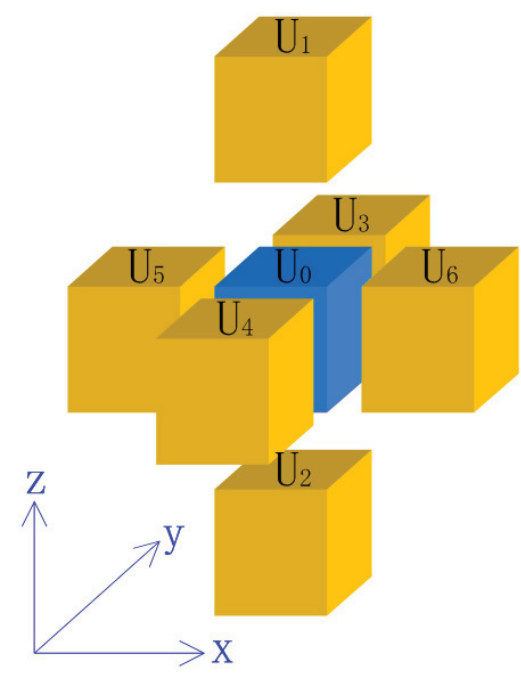

Figure 2. Data template.

likely to introduce errors into the estimation; therefore, the study uses the IDW method to estimate points not matched by the model and compensate for the uncertainty caused by global probability sampling. This method can also be regarded as a hybrid estimation method (M-I) of the MPG and the IDW.

The authors use the M-I, IDW, and OK methods to estimate the $\mathrm{Li}_{2} \mathrm{O}$ and $\mathrm{Ta}_{2} \mathrm{O}_{5}$ grades in porcelain clay and compare the estimation results with the sample grade by comparing deviation, trend, and variogram analyses. In the estimation process, the established 3-dimensional ore body model is used, and the block unit (block model) is divided based on the ore body model to store the estimated ore grade information. The block model and drill sample information are exported and saved in .txt format. MATLAB is used to read block information, implement the above estimates, and output the results.

\section{STUDY AREA}

An introduction to the regional geology, deposit geology, and ore grade characteristics of the porcelain ore mining areas is presented.

\subsection{Regional Geology of the Study Area}

The study area is located in the transition zone between the Yangtze and South China fold systems. The Jiuling uplift comprises the northern part of the study area, the central part is the Pingle depression and the south is the Wugong uplift. The uplift and depression contain two regional fault zones. The Yifeng-Jingdezhen and Pingxiang-Guangfeng faults control the distribution characteristics of the stratigraphic facies, magmatic rocks, and minerals in the area.

\subsubsection{Stratum}

The Jiu-Ling uplift, located within the Jiu-Gang uplift, is a set of large-scale oceanic turbidite deposits more than 2,000 metres thick composed of volcanic sediments. The Sinian system in the Wugong Uplift is a series of siliceous iron-bearing rocks with low-grade metamorphosed sandstone and siltstone with mudstone and conglomerate. The thickness of the Sinian system is 2000-10000 metres. Located on both sides of the Pingle depression and the uplift area, the Devonian-Triassic system is composed of a set of marine carbonates and terrigenous clastic sedimentary deposits, with a thickness of 3000-4000 metres. The fault basin next to the Shenda fault contains red clastic rocks and basalt with a thickness of 5000-7000 metres.

\subsubsection{Construction}

The study area is located in the southwestern Jiuling-Mekongshan thrust belt and the southern wing of the Jiuling compound anticline. It is located between the Yifeng-Jingdezhen deep fault zone a buried one and the Tongguxixiang-Fengxinshangfu fault.

The Jiuling uplift in the study area is composed of tight linear and double inverted folds. Fold axes trend northeast accompanied by a large-scale ductile shear zone. The fault structure is developed, and there are three large-scale faults in the north-north-east, north-east, and north-west directions. Most of the faults are pre-ore-formation structures, and the north-east and north-northeast faults have associated mineralization. In the Yanshanian period, rare metal ore-bearing hydrothermal fluids altered the alderite-type lithium-bearing porcelain ore body.

\subsubsection{Magmatic rocks}

From the Proterozoic to the Mesozoic, there has been abundant sub-magmatic activity, especially the Yanshanian magmatism associated with minerals containing W, Sn, and Rare Earth Elements (REEs). Due to the multi-stage nature of the magmatic activity, ore bodies commonly formed in complex rock masses or complex rock belts in the Jurassic or Early Cretaceous. The east channel of the Yifeng County-Gaoling-Baishuidong area is a complex rock belt dominated by Middle to Late Jurassic rocks. The lithology of the lithium-bearing porcelain ore body in this area is medium-fine-muddy-sodium feldspar-granite, and the genetic type is an altered alderite-type alkaline granite. In addition, a variety of associated rock drips and veins are developed in the area.

\subsection{Porcelain clay area geology}

The mining area, located in the Jiu-Gang uplift, has a complex lithology. Magmatic rocks are widely exposed in the mining area. Two lithium-bearing porcelain ore bodies exist in the mining area, named Li-1 and Li-2. Li-1 is the main ore body and is located in the eastern part of the mining area. $\mathrm{Li}-2$ is a sub-mineral body located in the western part of the mining area. The ore bodies occur in the shape of irregular veins or long strips, and the overall trend is approximately north-south. The ore bodies trend to the south, and the dip angle is steep and irregular. The surface of the F3 fault in the mining area is about $150 \mathrm{~m}$ at the surface of the 1624 line, and the drilling control tends to be about $180 \mathrm{~m}$ long. West of the F3 fault, the surface of the 12-0 line shows a width of approximately $150 \mathrm{~m}$, and the western end extends for $1000 \mathrm{~m}$ and becomes thinner in the vicinity of the 0 line. The 12-line control tends to be $100 \mathrm{~m}$ long, and the 0 -line control tends to be $30 \mathrm{~m}$ long. The $\mathrm{Li}-2$ ore body runs from the 13 th to the 5 th line in the southeast-northwest direction. The mineralization is uneven, showing irregular veins trending north, with an inclination of $45 \sim 60^{\circ}$ and an along- strike length of $340 \mathrm{~m}$. The northwest mineralization is wide, and it is cut off from the southeast by the 5th line.

\subsection{Three-dimensional geological model}

3D geological models are an important way to visualize ore bodies as well as an important process for future mine resource evaluation. Based on existing exploration data from the mining area, a 3-dimensional geological model and a geological database of the porcelain ore body are established (Fig. 3). The geological 


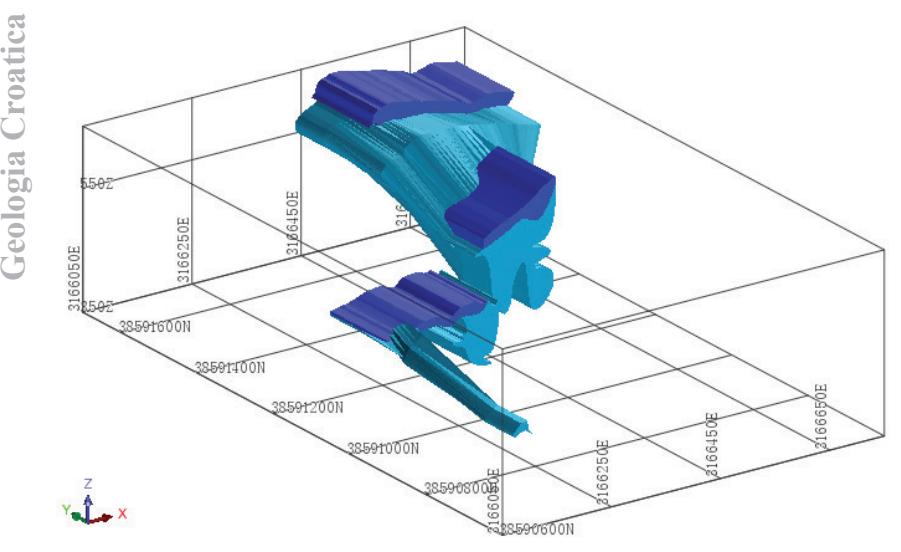

Figure 3. Three-dimensional model of the porcelain clay ore body.

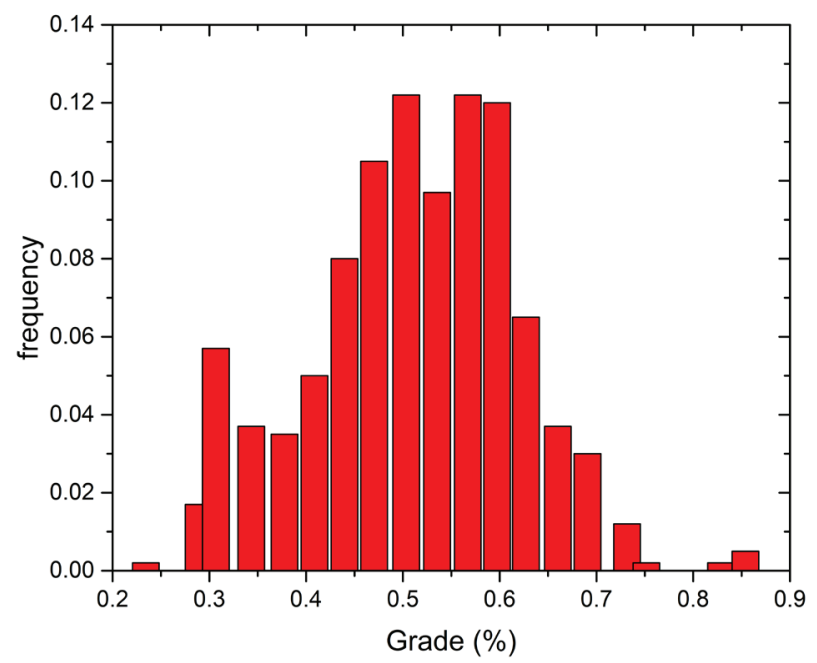

Figure 4. $\mathrm{Li}_{2} \mathrm{O}$ sample grade distribution.

database is built with the help of Surpac software. Establishment of the geological database includes three main processes: data structure construction, exploration engineering data preprocessing, and data importation. After the database is built, a 3D display of the borehole can be constructed. The ore body profile is delineated on the profile of the exploration line formed by the borehole. A 3D ore body model is built through the developed three-dimensional framework of the ore body. The geological database is mainly used to store the acquired exploration engineering data,

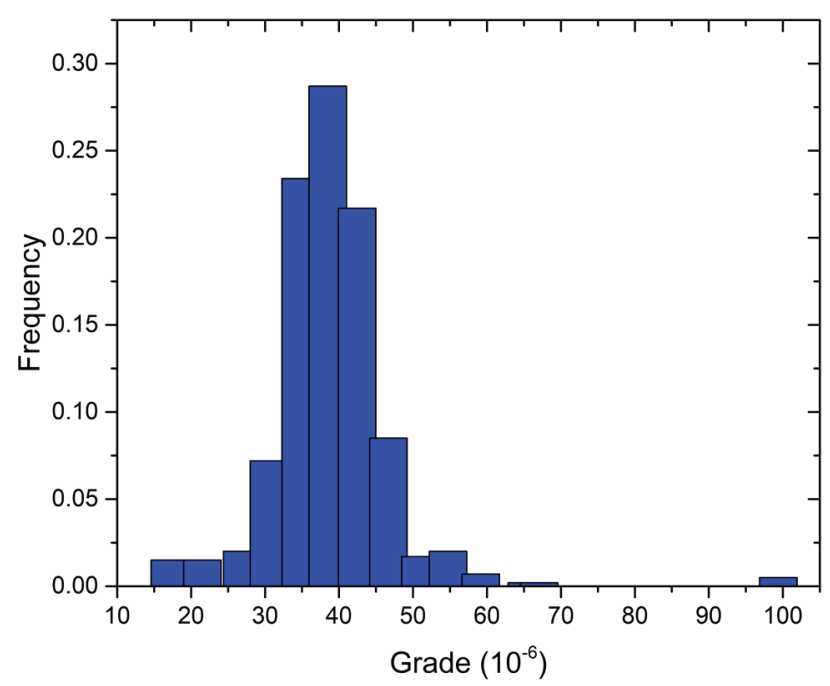

Figure 5. $\mathrm{Ta}_{2} \mathrm{O}_{5}$ sample grade distribution.

and the sample grade combination can be performed on the stored exploration engineering data.

\subsection{Porcelain clay samples}

Firstly, the original $\mathrm{Li}_{2} \mathrm{O}$ and $\mathrm{Ta}_{2} \mathrm{O}_{5}$ sample grades were combined using the Surpac software sample combination tool. The composite sample is finally produced, and the $\mathrm{Li}_{2} \mathrm{O}$ and $\mathrm{Ta}_{2} \mathrm{O}_{5}$ grades of porcelain clay samples are determined based on the geological database (Table 1). Fig. 4 and 5 show the $\mathrm{Li}_{2} \mathrm{O}$ and $\mathrm{Ta}_{2} \mathrm{O}_{5}$ grade histograms, respectively.

\section{VARIOGRAM AND TRAINING IMAGES}

Descriptions of the ore body test variogram calculation using the OK method follow. The fitting parameters of the spherical variogram and fractal variogram are determined. The block model is used as the training image for grade estimation using the MPG method, and block models of different sizes are established to test the effect of block size on the estimation results.

\subsection{Variogram fitting for porcelain clay}

The spherical, power function, and fractal models were used to fit the experimental variogram for the sample grade of porcelain clay, and fitting parameters for the $\mathrm{Li}_{2} \mathrm{O}$ and $\mathrm{Ta}_{2} \mathrm{O}_{5}$ grades in the $\mathrm{X}, \mathrm{Y}$, and $\mathrm{Z}$ directions were obtained. In the spherical model fit-

Table 1. $\mathrm{Li}_{2} \mathrm{O}$ and $\mathrm{Ta}_{2} \mathrm{O}_{5}$ grade statistics results of porcelain clay.

\begin{tabular}{|c|c|c|c|c|c|c|c|c|c|}
\hline Name & Min & Max & Average & Variance & $\begin{array}{l}\text { Standard } \\
\text { Deviation }\end{array}$ & Median & Kurtosis & Skewness & $\begin{array}{c}\text { Coefficient of } \\
\text { variation }\end{array}$ \\
\hline $\mathrm{Li}_{2} \mathrm{O}(\%)$ & 0.2343 & 0.8679 & 0.51165 & 0.01193 & 0.10923 & 0.5183 & -0.1208 & -0.0729 & 0.21349 \\
\hline
\end{tabular}

Table 2. Fitting parametersfor $\mathrm{Li}_{2} \mathrm{O}$ and $\mathrm{Ta}_{2} \mathrm{O}_{5}$ grade in the spherical model.

\begin{tabular}{|c|c|c|c|c|c|}
\hline Name & Direction & $\mathrm{C}_{0}$ & $C$ & $\mathrm{C}_{0}+\mathrm{C}$ & a \\
\hline \multirow{3}{*}{$\mathrm{Li}_{2} \mathrm{O}$} & $x$ & 0.0045 & 0.0043 & 0.0088 & 37.15 \\
\hline & Y & 0.0045 & 0.0043 & 0.0088 & 37.15 \\
\hline & Z & 0.0029 & 0.0058 & 0.00087 & 67.61 \\
\hline \multirow{3}{*}{$\mathrm{Ta}_{2} \mathrm{O}_{5}$} & $x$ & 18.05 & 48.31 & 66.36 & 27.69 \\
\hline & $Y$ & 18.05 & 48.31 & 66.36 & 27.69 \\
\hline & Z & 6.17 & 51.94 & 58.11 & 32.76 \\
\hline
\end{tabular}


Table 3. Fitting parameters for $\mathrm{Li}_{2} \mathrm{O}$ and $\mathrm{Ta}_{2} \mathrm{O}_{5}$ grade in the power function model and the fractal model.

\begin{tabular}{|c|c|c|c|c|c|c|c|c|c|c|}
\hline \multirow{2}{*}{ Name } & \multirow{2}{*}{ Direction } & \multirow{2}{*}{ Model } & \multicolumn{5}{|c|}{ Model evaluation } & \multicolumn{3}{|c|}{ Model parameter } \\
\hline & & & R-square & $\mathrm{F}$ & df1 & df2 & Sig. & Constant & b1 & b2 \\
\hline \multirow{6}{*}{$\mathrm{Li}_{2} \mathrm{O}$} & \multirow{2}{*}{$x$} & power & 0.777 & 62.888 & 1 & 18 & 0 & -5.584 & 0.217 & -- \\
\hline & & fractal & 0.894 & 71.652 & 2 & 17 & 0 & -6.049 & 0.623 & -0.074 \\
\hline & \multirow{2}{*}{$\mathrm{Y}$} & power & 0.777 & 62.888 & 1 & 18 & 0 & -5.584 & 0.217 & -- \\
\hline & & fractal & 0.894 & 71.652 & 2 & 17 & 0 & -6.049 & 0.623 & -0.074 \\
\hline & \multirow{2}{*}{ Z } & power & 0.899 & 160.768 & 1 & 18 & 0 & -6.487 & 0.425 & -- \\
\hline & & fractal & 0.954 & 174.703 & 2 & 17 & 0 & -7.065 & 0.929 & -0.091 \\
\hline \multirow{6}{*}{$\mathrm{Ta}_{2} \mathrm{O}_{5}$} & \multirow{2}{*}{$x$} & power & 0.599 & 26.925 & 1 & 18 & 0 & 3.103 & 0.279 & -- \\
\hline & & fractal & 0.787 & 31.429 & 2 & 17 & 0 & 2.24 & 1.031 & -0.137 \\
\hline & \multirow{2}{*}{ Y } & power & 0.599 & 26.925 & 1 & 18 & 0 & 3.103 & 0.279 & -- \\
\hline & & fractal & 0.787 & 31.429 & 2 & 17 & 0 & 2.24 & 1.031 & -0.137 \\
\hline & \multirow{2}{*}{ Z } & power & 0.805 & 74.218 & 1 & 18 & 0 & 2.372 & 0.432 & -- \\
\hline & & fractal & 0.91 & 86.075 & 2 & 17 & 0 & 1.508 & 1.186 & -0.137 \\
\hline
\end{tabular}
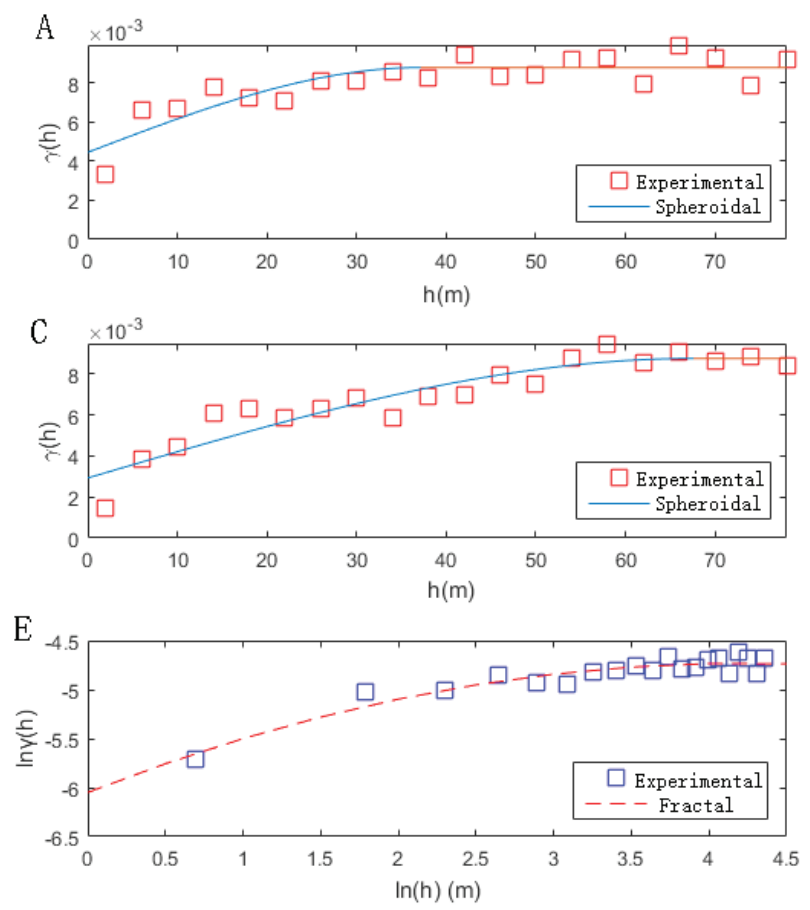
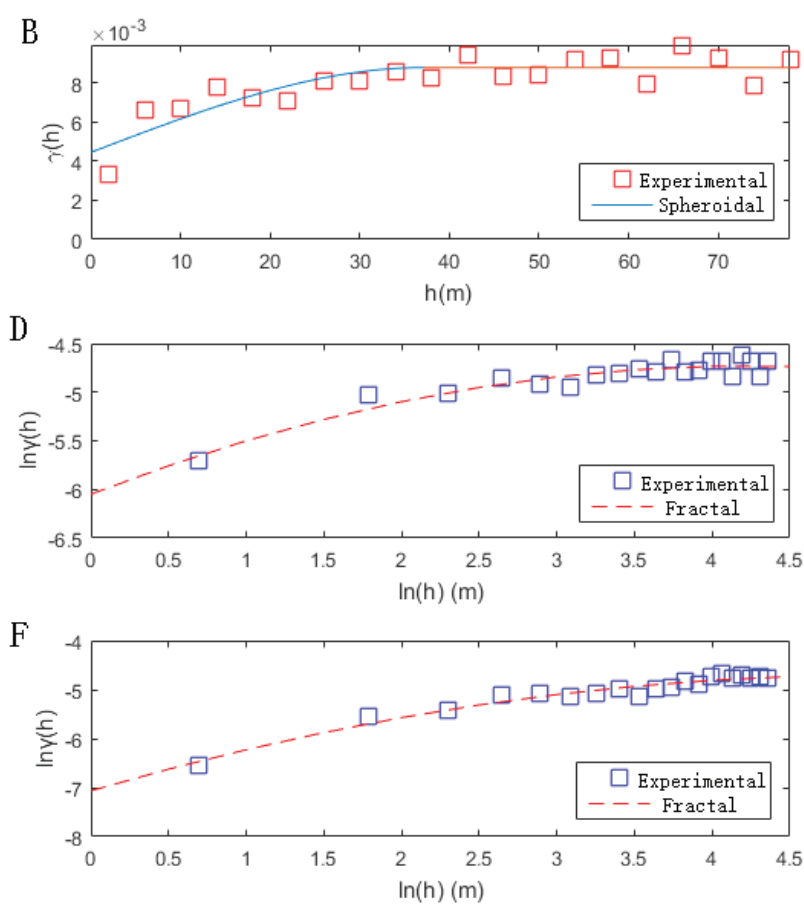

Figure 6. Variogram fitting results of $\mathrm{Li}_{2} \mathrm{O}$ grade. $\mathrm{A}, \mathrm{B}$, and $\mathrm{C}$ are the fit using the spherical model in the $\mathrm{X}, \mathrm{Y}$, and $\mathrm{Z}$ directions, respectively. $\mathrm{D}$, $\mathrm{E}$, and $\mathrm{F}$ are the fit using the fractal model in the $X, Y$, and $Z$ directions respectively.

ting, the existing spherical model fitting tool in MATLAB was used. Table 2. shows the spherical model fitting parameters for the $\mathrm{Li}_{2} \mathrm{O}$ and $\mathrm{Ta}_{2} \mathrm{O}_{5}$ grades. Table 3. shows fitting parameters for the power function and fractal models.

The fractal and power function models were used for variogram fitting. First, the fractal and power function models were converted into logarithmic form. Then, the SPSS tool was used to fit the experimental variogram. Table 3 . gives the fitting parameters of the fractal and power function models. The fractal model belongs to the variogram model without sill. According to the fitting for $\mathrm{Li}_{2} \mathrm{O}$ grade in the fractal and power function models, the $\mathrm{R}$-square is above 0.89 and the significance (Sig.) is below 0.05 in the fractal model; hence, its fit is better than that the power ex- ponential function model. Based on the fitting of $\mathrm{Ta}_{2} \mathrm{O}_{5}$ grade, the fit of the fractal model is better than the spherical model. The $\mathrm{R}$-squares in the $\mathrm{X}$ direction and $\mathrm{Y}$ direction are above 0.78 , and the significance is below 0.05 . So the fitting effect is acceptable. The R-square of the fractal model is 0.91 , and the significance is below 0.05 ; hence, the fitting effect is better than the spherical model.

\subsection{Training image construction}

The training image is a representation of the a priori geological model. Previous studies have indicated that a training image can be constructed by unconditional simulations, analog layer simulations, or using digitized images sketched by geologists. It is dif- 

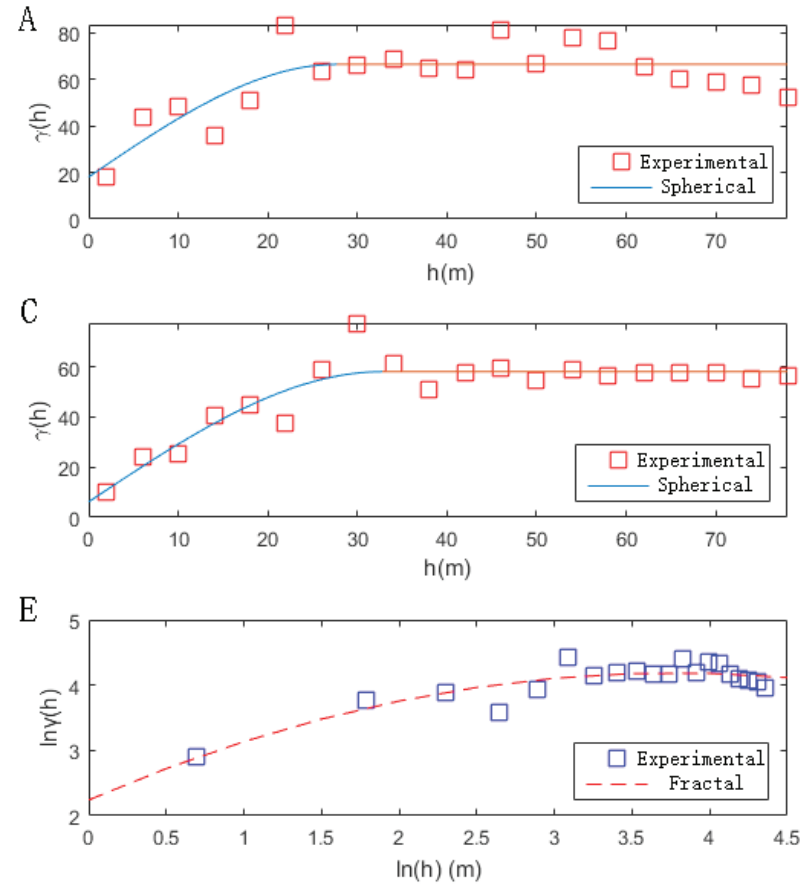
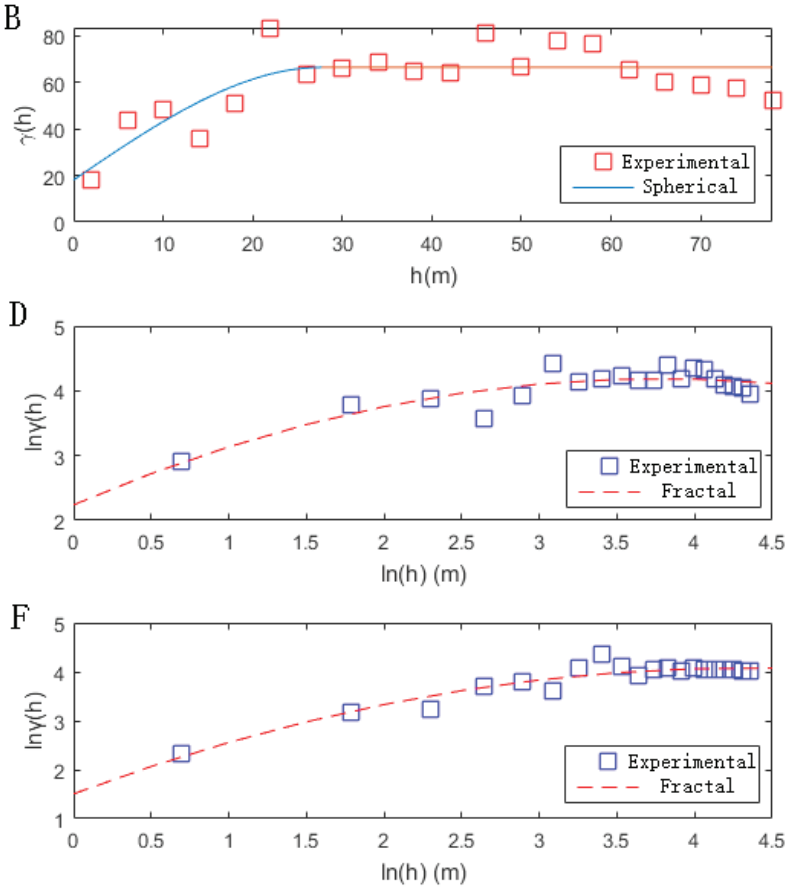

Figure 7. Variogram fitting results of $\mathrm{Ta}_{2} \mathrm{O}_{5}$ grad. $\mathrm{A}, \mathrm{B}$, and $\mathrm{C}$ are the fit of the spherical model in the $\mathrm{X}, \mathrm{Y}$, and $\mathrm{Z}$ directions, respectively. $\mathrm{D}$, $\mathrm{E}$, and $\mathrm{F}$ are the fit of the fractal model in the $X, Y$, and $Z$ directions, respectively.

Table 4. Block sizes of training images (pixel number).

\begin{tabular}{lccccc}
\hline Image name & Image 1 & Image 2 & Image 3 & Image 4 & Image 5 \\
\hline X-direction (m) & 75 & 75 & 75 & 38 & 38 \\
Y-direction (m) & 150 & 75 & 75 & 75 & 75 \\
Z-direction (m) & 4 & 4 & 2 & 4 & 2 \\
\hline
\end{tabular}

ficult to directly determine the grade distribution pattern of the ore body in grade estimation. It is important to establish a simple and effective training image for ore body grade estimation; therefore, the authors assign the sample point grade to the nearest block in the block model and build a 3-dimensional training image based on the block model. The establishment of the block model is primarily accomplished by selecting the block range, determining the block size, adding block attributes, adding block constraints, and block assignment. The block range in this study should be slightly larger than the ore body range. A block model is constructed using a variety of block sizes (Table 4). Block assignments are primarily determined using the nearest distance method. Table 4. shows the block size parameters in five training images. This study uses multiple training images to obtain several estimated grades and determines the optimal $\mathrm{Li}_{2} \mathrm{O}$ and $\mathrm{Ta}_{2} \mathrm{O}_{5}$ grade estimation parameters.

The block size in Figs. 7. and 8. is $150 \mathrm{~m} \times 75 \mathrm{~m} \times 4 \mathrm{~m}$.

The length, width, and height of the training images of porcelain clay are $1050 \mathrm{~m}, 675 \mathrm{~m}$, and $224 \mathrm{~m}$, respectively. Figs. 8 . and 9. are training images of $\mathrm{Li}_{2} \mathrm{O}$ and $\mathrm{Ta}_{2} \mathrm{O}_{5}$, respectively.

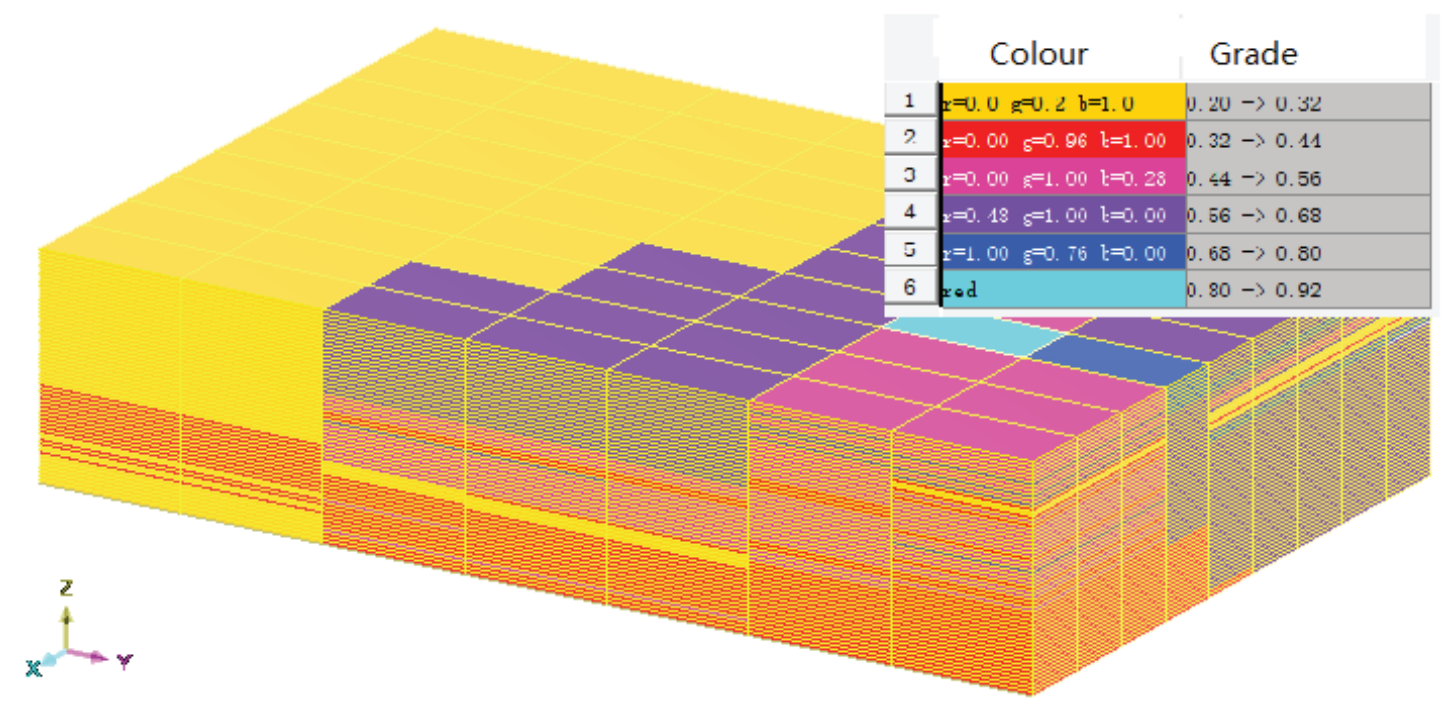

Figure 8. $\mathrm{Li}_{2} \mathrm{O}$ training image. 


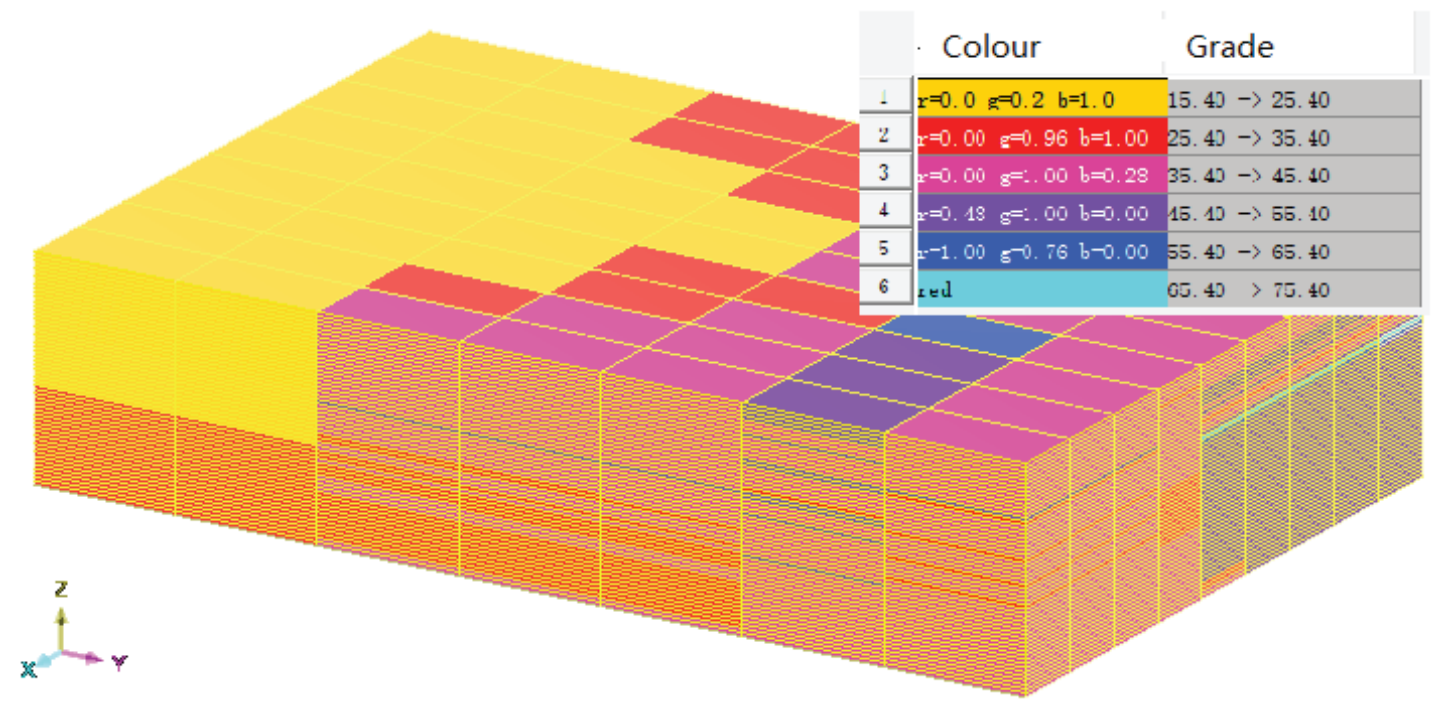

Figure 9. $\mathrm{Ta}_{2} \mathrm{O}_{5}$ training image

\section{ESTIMATION RESULTS AND ANALYSIS}

The estimated features from the M-I method were analyzed, and optimal estimation results for $\mathrm{Li}_{2} \mathrm{O}$ and $\mathrm{Ta}_{2} \mathrm{O}_{5}$ determined. The estimation result of the M-I method was compared with the IDW and $\mathrm{OK}$ methods. The optimal estimation results of $\mathrm{Li}_{2} \mathrm{O}$ and $\mathrm{Ta}_{2} \mathrm{O}_{5}$ grades of porcelain clay using the IDW, OK, and M-I methods were compared. The deviations, trends, and variogram analysis were examined in order to estimate ore grade quality.

Table 5. Estimated grade statistics for $\mathrm{Li}_{2} \mathrm{O}$.

\begin{tabular}{|c|c|c|c|c|c|c|c|c|c|c|}
\hline $\begin{array}{l}\text { Training } \\
\text { images }\end{array}$ & $\begin{array}{l}\text { Discrete } \\
\text { intervals }\end{array}$ & $\operatorname{Min}(\%)$ & $\operatorname{Max}(\%)$ & Average (\%) & variance & $\begin{array}{l}\text { Standard } \\
\text { deviation }\end{array}$ & median & Kurtosis & Skewness & $\begin{array}{l}\text { Coefficient } \\
\text { of variation }\end{array}$ \\
\hline \multirow{6}{*}{ Image 1} & 4 & 0.277 & 0.824 & 0.480 & 0.012 & 0.112 & 0.472 & -0.030 & -0.909 & 0.233 \\
\hline & 6 & 0.277 & 0.824 & 0.483 & 0.011 & 0.104 & 0.498 & -0.220 & -0.451 & 0.215 \\
\hline & 8 & 0.274 & 0.824 & 0.485 & 0.012 & 0.107 & 0.512 & -0.423 & -0.464 & 0.221 \\
\hline & 10 & 0.266 & 0.824 & 0.487 & 0.010 & 0.101 & 0.484 & 0.037 & -0.610 & 0.207 \\
\hline & 12 & 0.261 & 0.824 & 0.488 & 0.010 & 0.101 & 0.495 & -0.106 & -0.545 & 0.208 \\
\hline & 14 & 0.277 & 0.824 & 0.485 & 0.011 & 0.105 & 0.483 & -0.137 & -0.660 & 0.216 \\
\hline \multirow{6}{*}{ Image 2} & 4 & 0.277 & 0.798 & 0.477 & 0.012 & 0.108 & 0.472 & -0.035 & -0.766 & 0.228 \\
\hline & 6 & 0.277 & 0.824 & 0.486 & 0.012 & 0.110 & 0.498 & -0.153 & -0.437 & 0.226 \\
\hline & 8 & 0.274 & 0.824 & 0.488 & 0.012 & 0.110 & 0.512 & -0.344 & -0.390 & 0.225 \\
\hline & 10 & 0.266 & 0.824 & 0.497 & 0.011 & 0.103 & 0.519 & -0.100 & -0.462 & 0.206 \\
\hline & 12 & 0.274 & 0.824 & 0.489 & 0.010 & 0.102 & 0.517 & -0.171 & -0.595 & 0.208 \\
\hline & 14 & 0.277 & 0.824 & 0.490 & 0.011 & 0.106 & 0.498 & -0.192 & -0.625 & 0.216 \\
\hline \multirow{6}{*}{ Image 3} & 4 & 0.314 & 0.798 & 0.481 & 0.011 & 0.107 & 0.472 & -0.084 & -0.743 & 0.223 \\
\hline & 6 & 0.277 & 0.824 & 0.487 & 0.012 & 0.108 & 0.498 & -0.244 & -0.438 & 0.222 \\
\hline & 8 & 0.274 & 0.824 & 0.484 & 0.012 & 0.111 & 0.512 & -0.241 & -0.432 & 0.230 \\
\hline & 10 & 0.266 & 0.818 & 0.496 & 0.010 & 0.101 & 0.519 & -0.145 & -0.650 & 0.203 \\
\hline & 12 & 0.277 & 0.824 & 0.490 & 0.010 & 0.102 & 0.525 & -0.279 & -0.590 & 0.207 \\
\hline & 14 & 0.277 & 0.824 & 0.489 & 0.011 & 0.106 & 0.520 & -0.273 & -0.679 & 0.217 \\
\hline \multirow{6}{*}{ Image 4} & 4 & 0.277 & 0.798 & 0.483 & 0.012 & 0.112 & 0.472 & -0.051 & -0.845 & 0.231 \\
\hline & 6 & 0.277 & 0.824 & 0.482 & 0.013 & 0.113 & 0.498 & -0.116 & -0.614 & 0.234 \\
\hline & 8 & 0.274 & 0.828 & 0.490 & 0.013 & 0.114 & 0.512 & -0.147 & -0.082 & 0.233 \\
\hline & 10 & 0.266 & 0.836 & 0.497 & 0.010 & 0.101 & 0.519 & -0.151 & -0.440 & 0.204 \\
\hline & 12 & 0.277 & 0.842 & 0.489 & 0.010 & 0.101 & 0.518 & -0.169 & -0.493 & 0.206 \\
\hline & 14 & 0.277 & 0.824 & 0.489 & 0.011 & 0.105 & 0.503 & -0.201 & -0.591 & 0.215 \\
\hline \multirow{6}{*}{ Image 5} & 4 & 0.314 & 0.798 & 0.484 & 0.012 & 0.109 & 0.472 & -0.091 & -0.834 & 0.225 \\
\hline & 6 & 0.277 & 0.824 & 0.486 & 0.012 & 0.111 & 0.498 & -0.240 & -0.584 & 0.228 \\
\hline & 8 & 0.274 & 0.824 & 0.484 & 0.013 & 0.113 & 0.512 & -0.247 & -0.479 & 0.233 \\
\hline & 10 & 0.266 & 0.836 & 0.496 & 0.010 & 0.101 & 0.519 & -0.123 & -0.662 & 0.205 \\
\hline & 12 & 0.277 & 0.842 & 0.491 & 0.010 & 0.102 & 0.525 & -0.286 & -0.544 & 0.208 \\
\hline & 14 & 0.277 & 0.845 & 0.491 & 0.012 & 0.109 & 0.524 & -0.143 & -0.433 & 0.221 \\
\hline
\end{tabular}


Table 6. Estimated grade statistics for $\mathrm{Ta}_{2} \mathrm{O}_{5}$

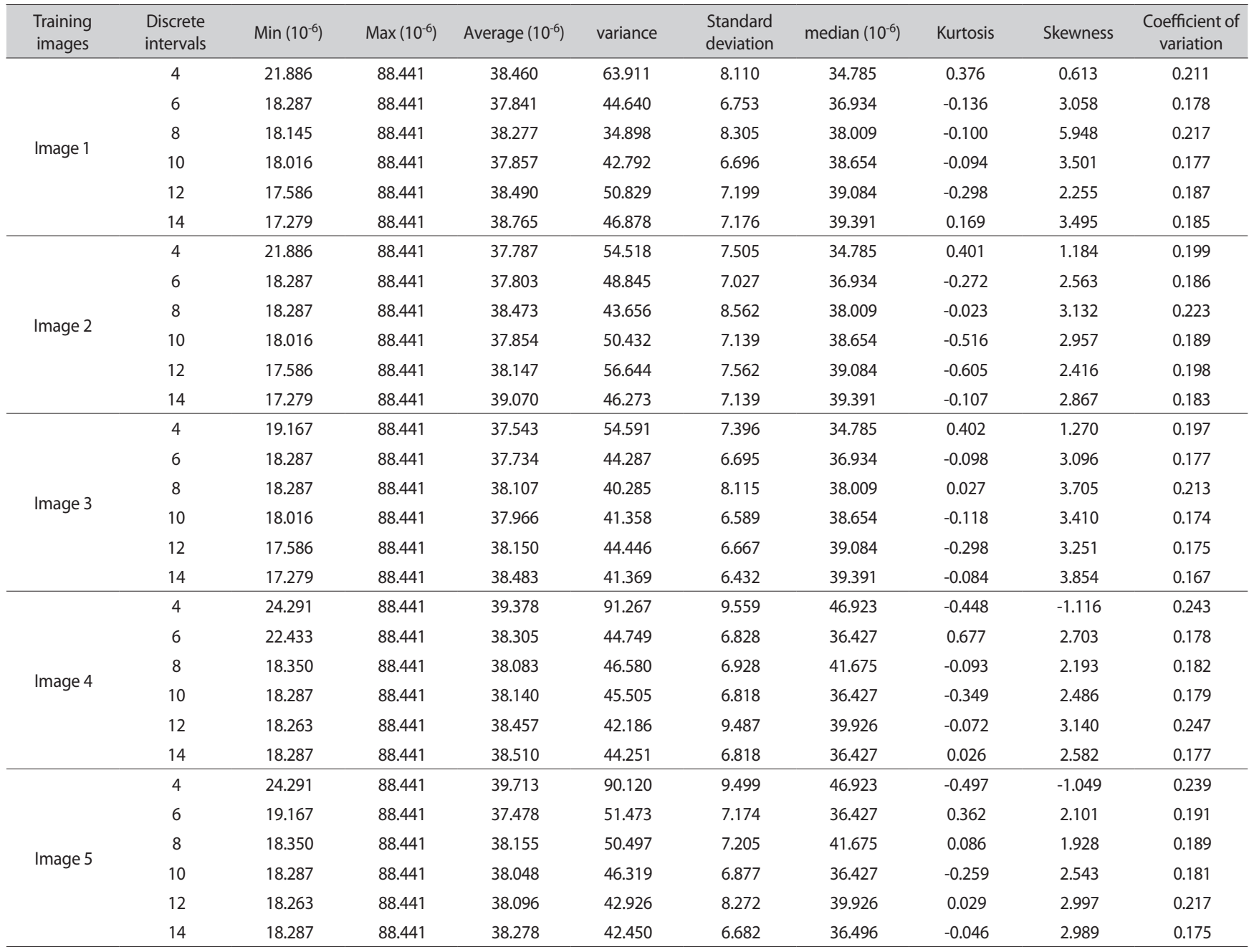

\subsection{Estimation results}

Firstly, the estimation results of the M-I method using different training images were calculated, and the optimal estimation results determined. Similarly, the optimal results of $\mathrm{Li}_{2} \mathrm{O}$ and $\mathrm{Ta}_{2} \mathrm{O}_{5}$ estimated using the IDW and OK methods are given.

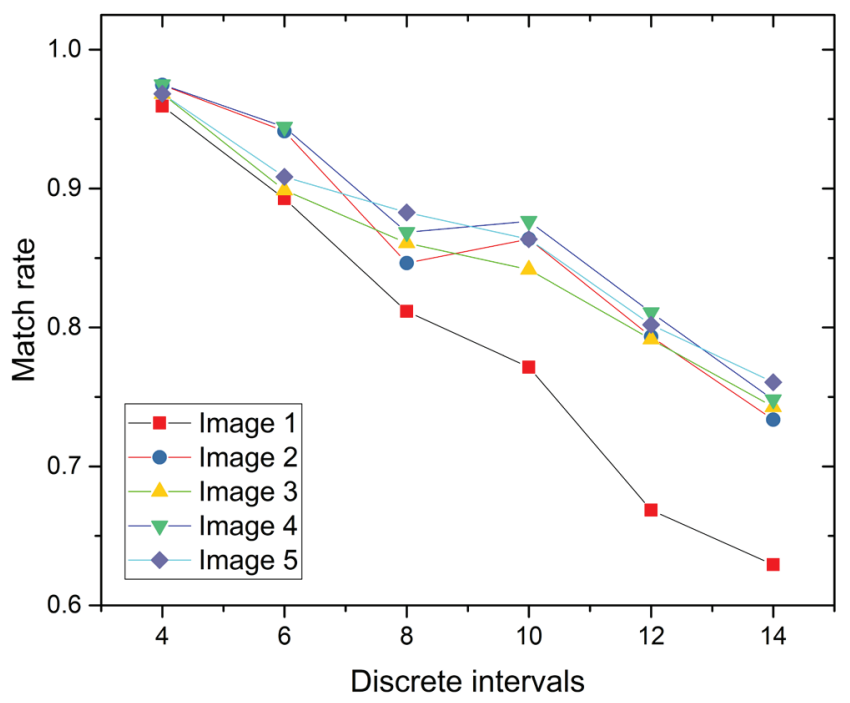

Figure 10. Data event and data pattern matching rates of $\mathrm{Li}_{2} \mathrm{O}$.

\subsubsection{M-I estimation results}

$\mathrm{Li}_{2} \mathrm{O}$ and $\mathrm{Ta}_{2} \mathrm{O}_{5}$ grades in porcelain clay ore were evaluated using the M-I method. The estimation characteristics of the M-I method were analyzed using the deviation between valuation grade and sample grade.

\section{Results and analysis of $\mathrm{Li}_{2} \mathrm{O}$ grade valuation}

Table 5. shows the results of the $\mathrm{Li}_{2} \mathrm{O}$ grade estimation using the M-I method.

From the data event and data pattern matching rate in Fig. 10 , the number of discrete intervals increases, which reduces the successful matching probability. At this time, more data points use the overall probability instead of the local probability in the valuation. In the M-I method, the number of points to be estimated using the IDW method increases as the number of discrete intervals increases, which has a gradual upward trend. In terms of influence of the number of pixels in the training image on matching rate, the high-pixel training image has a somewhat improved matching.

Fig. 11A. shows the minimum deviation in $\mathrm{Li}_{2} \mathrm{O}$ valuation grade. In the M-I method, increasing number of pixels in the training image has no noticeable effect on the estimated minimum deviation. For training image 1 with 12 discrete intervals, the smallest minimum deviation is $11.27 \%$.

Fig. 11B. shows the maximum deviation in $\mathrm{Li}_{2} \mathrm{O}$ valuation grade. As the number of discrete intervals increases, the maxi- 

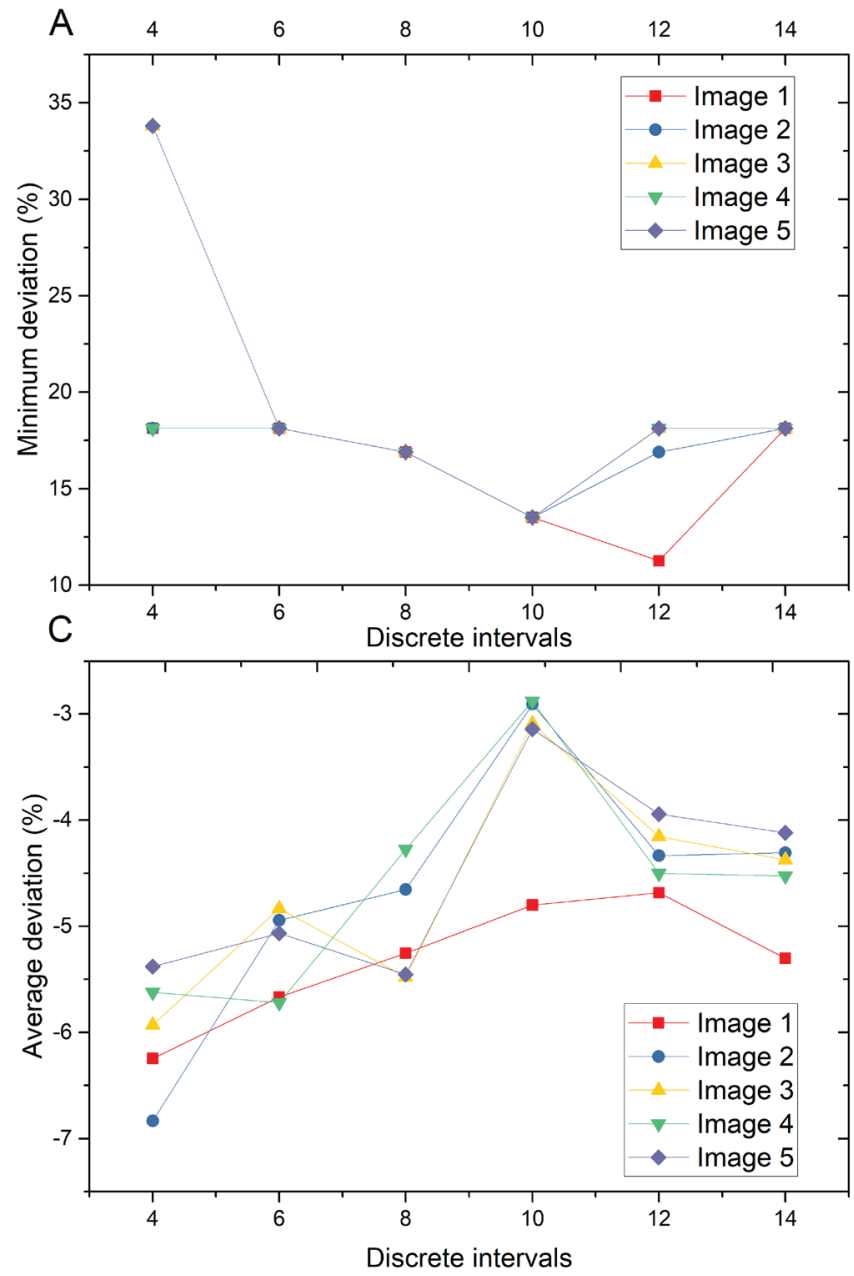

Figure 11. Deviation in $\mathrm{Li}_{2} \mathrm{O}$ grade estimation based on integrated approach.

mum deviation decreases. When the resolution of the training image is high, the decrease in maximum deviation becomes more obvious, indicating that increasing the training image pixels can reduce the maximum deviation. When training image 5 is used and the number of discrete intervals is 14 , the smallest maximum deviation is $-2.61 \%$.

Fig. $11 \mathrm{C}$. shows the $\mathrm{Li}_{2} \mathrm{O}$ valuation grade average deviation, indicating that a larger number of training image pixels can reduce maximum deviation. As the number of discrete intervals increases, average deviation decreases first and then increases. An inflection point occurs when the number of discrete intervals is 10 . As the matching ratio decreases (Fig.10), the number of discrete intervals and estimated deviation will increase. When training image 4 is used and the number of discrete intervals is 10 , the smallest average deviation is $-2.88 \%$.

The deviation of estimated $\mathrm{Li}_{2} \mathrm{O}$ grade standard deviation is estimated using the M-I method (Fig. 11D). On the one hand, the deviation of the standard deviation variation trend is affected by the number of discrete intervals; on the other hand, it is affected by the matching rate of data events to data patterns. When training image 5 is used and the number of discrete intervals is 14 , the $\mathrm{Li}_{2} \mathrm{O}$ grade minimum deviation using the $\mathrm{M}-\mathrm{I}$ method is $-0.54 \%$.

The four graphs A, B, C, and D are the estimated deviations of the minimum, maximum, average, and deviation of standard deviation of the estimated $\mathrm{Li}_{2} \mathrm{O}$ grade, respectively.
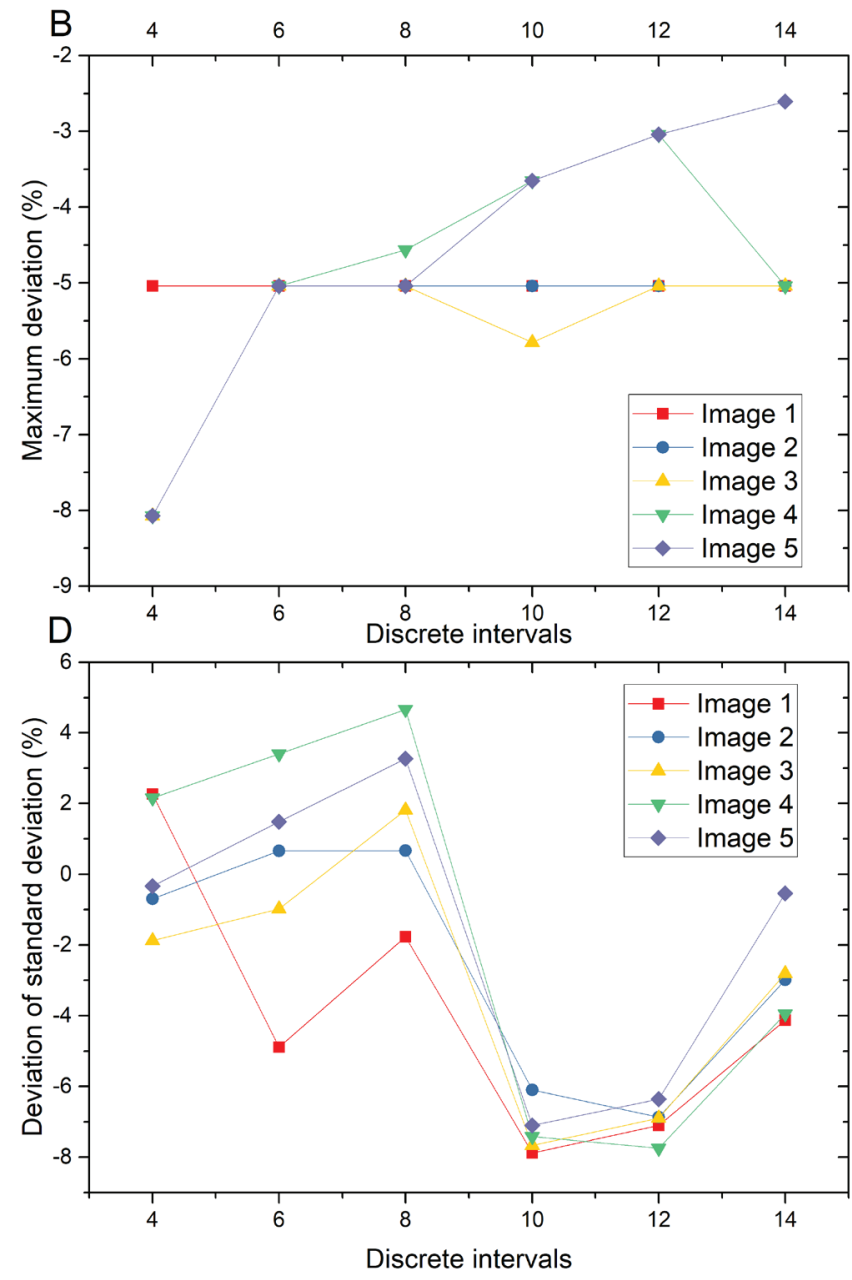

Comprehensive analysis of Fig. 11. shows that the M-I method can effectively improve $\mathrm{Li}_{2} \mathrm{O}$ grade estimation, and the number of discrete intervals can improve estimation accuracy. In addition, the excessive number of calculation intervals (10 or more) reduces the valuation effect. When the number of training image pixels is large, the success rate between the data event and data template can be improved, which helps to improve and stabilize the evaluation. The M-I method with training image 5 and 10 discrete intervals has the best evaluation. It is estimated that the minimum deviation of the $\mathrm{Li}_{2} \mathrm{O}$ grade is $13.52 \%$, the maximum deviation is $-3.65 \%$, the average deviation is $-3.14 \%$, and the deviation of the standard deviation is $-7.10 \%$.

\section{Results and analysis of $\mathrm{Ta}_{2} \mathrm{O}_{5}$ grade valuation}

Table 6. shows the $\mathrm{Ta}_{2} \mathrm{O}_{5}$ grade estimated using the M-I method.

Figure 12. shows the data event and data pattern matching rate for the M-I method. Increasing the number of training image pixels can improve the matching rate. The highest number of training image pixels has the highest matching rate, and the training image with the lowest number of pixels has a lower matching rate. Upgrading the training image in the $\mathrm{Ta}_{2} \mathrm{O}_{5}$ grade evaluation can help reduce the use of global probability sampling in the valuation process and thus improve valuation accuracy. $\mathrm{Li}_{2} \mathrm{O}$ grade estimation shows a similar relationship between matching ratio and number of training image pixels. The effect of the training image on matching efficiency is related to the sample distribution form or sampling method. The M-I method is affected by the 


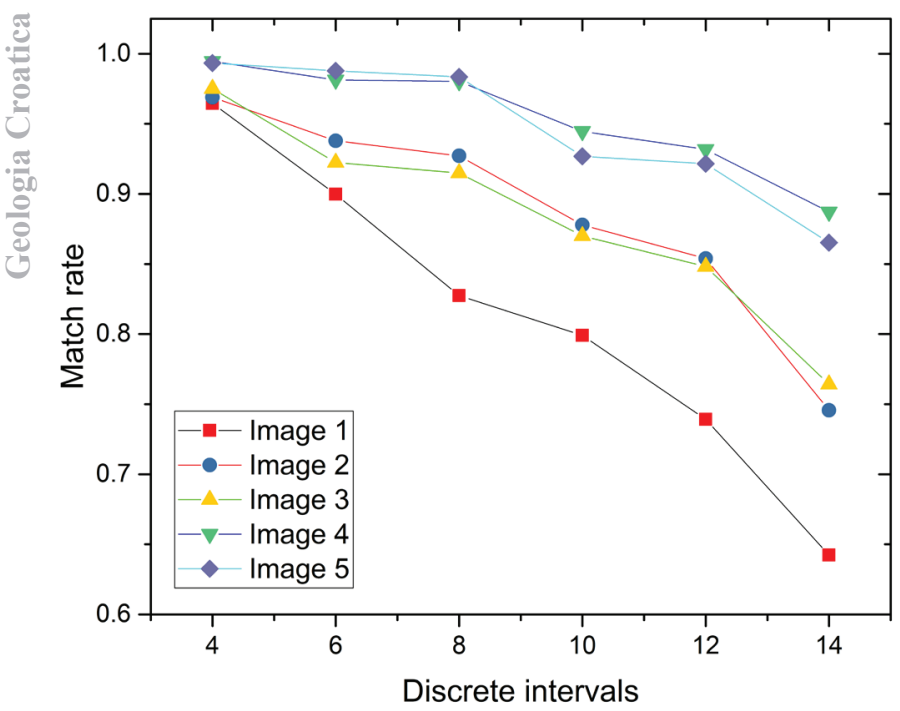

Figure 12. Data event and data pattern matching rates of $\mathrm{Ta}_{2} \mathrm{O}_{5}$.

sample grade distribution or sampling method when estimating the ore grade.

Figure 13. presents an analysis of the estimated $\mathrm{Ta}_{2} \mathrm{O}_{5}$ deviation when using the $\mathrm{M}-\mathrm{I}$ method. The effect of training image pixels on the minimum deviation is not significant (Fig. 13A).
After the number of discrete intervals increases, the minimum deviation decreases. When using training image 1,2 , or 3 with 14 discrete intervals, the smallest minimum deviation is $11.94 \%$.

Figure 13B shows the maximum deviation of the $\mathrm{Ta}_{2} \mathrm{O}_{5}$ valuation grade. The number of discrete intervals and the pixel size of the training image have no affect on the maximum deviation. The maximum deviation is consistently $11.03 \%$. Increasing the number of training image pixels fails to reduce the average deviation (Fig. 13C), indicating that the valuation results are affected by the IDW method when using the M-I method. The average deviation of the M-I method is smaller than the MPG method, indicating that the M-I method is still superior to the simple MPG method. When using training image 2 with 14 discrete intervals, the smallest minimum deviation is $0.35 \%$.

Figure 13D. shows the deviation of the standard deviation of the $\mathrm{Ta}_{2} \mathrm{O}_{5}$ valuation grade. Under the M-I method, the deviation of standard deviation fluctuates greatly with the number of discrete intervals. However, compared with the MPG method, the M-I method shows a significant reduction in deviation of the standard deviation.

This study concludes that the use of the M-I method, training image 4, and 14 discrete intervals provides the best results. It is estimated that the minimum deviation of the $\mathrm{Ta}_{2} \mathrm{O}_{5}$ grade is $18.31 \%$, the maximum deviation is $-11.03 \%$, the average deviation is $-2.15 \%$, and the deviation of the standard deviation is $2.19 \%$. The $\mathrm{Ta}_{2} \mathrm{O}_{5}$ valuation shows that the M-I method is closer to the
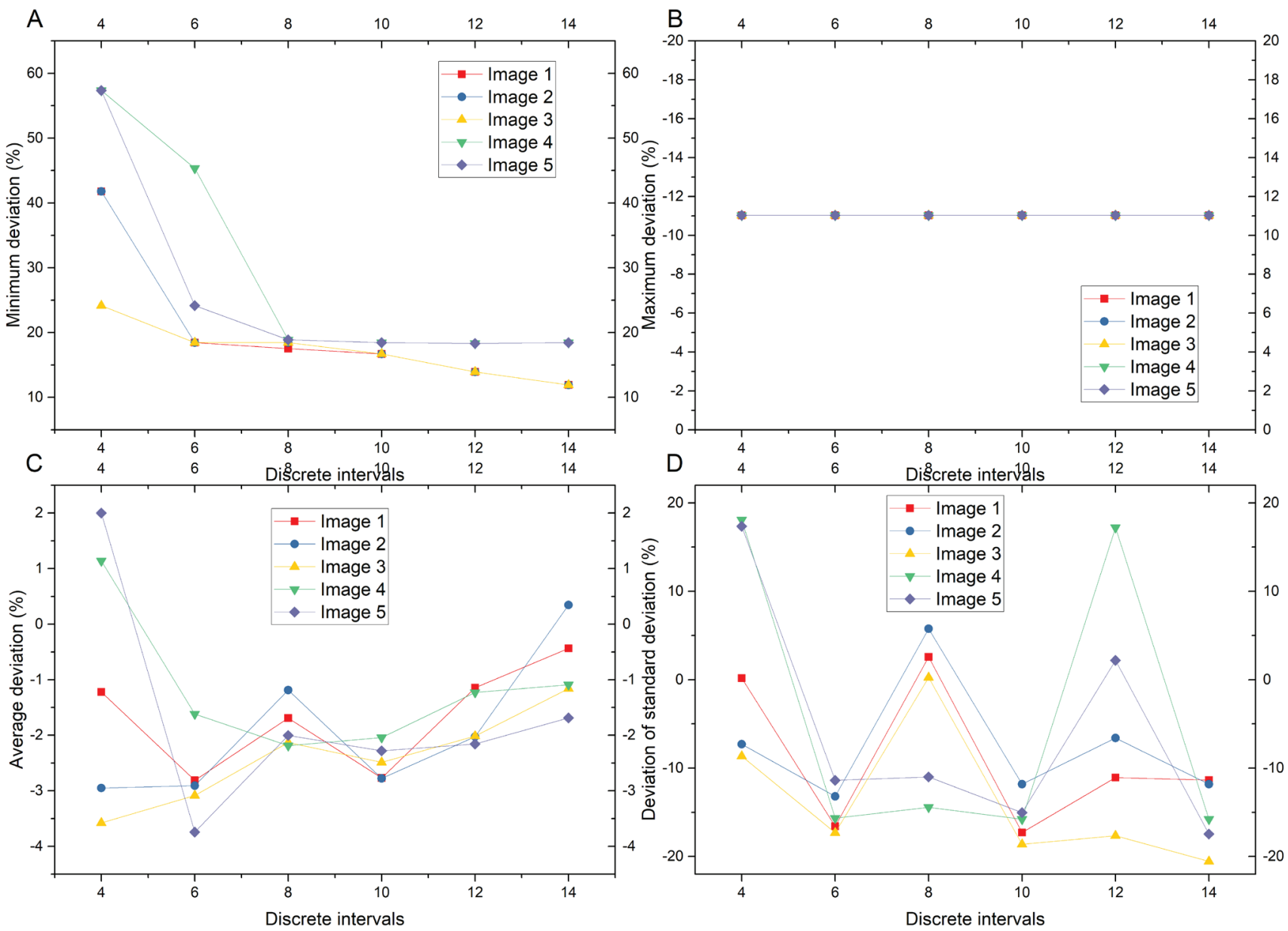

Figure 13. Deviation in $\mathrm{Ta}_{2} \mathrm{O}_{5}$ grade estimation based on integrated approach. 
sample $\mathrm{Ta}_{2} \mathrm{O}_{5}$ grade distribution than the MPG method, indicating the M-I method is superior to the MPG method. The M-I method is not scientific and rigorous enough to use global sampling instead of overall sampling for data events that cannot be matched. Increasing the number of discrete intervals reduces the matching rate between data events and data templates, which increases the probability of using global sampling to generate local samples. This increases the inaccuracy of the valuation. Increasing the number of training image pixels can improve the matching rate to a certain extent but cannot fundamentally solve the problems outlined above. The IDW is used instead of the global sample estimate for points that cannot be estimated using local sampling. Although the IDW method has a certain smoothing effect, its valuation results are better than estimates determined using global sampling. Because data events around the point to be estimated cannot be used, it is commonly the case that there is a small probability of data events; therefore, it is unscientific to use global sampling instead of local sampling.

The four graphs A, B, C, and D show the estimated deviations of the minimum, maximum, average, and deviation of standard deviation of the estimated $\mathrm{Ta}_{2} \mathrm{O}_{5}$ grade, respectively.

\subsubsection{Optimal estimation results}

The optimal estimated grades of $\mathrm{Li}_{2} \mathrm{O}$ and $\mathrm{Ta}_{2} \mathrm{O}_{5}$ are shown in Tables 7 and 8, respectively. IDW1 and IDW2 respectively represent the optimal estimation results when the three samples and five samples of $\mathrm{Li}_{2} \mathrm{O}$ and $\mathrm{Ta}_{2} \mathrm{O}_{5}$ were included in the estimation of IDW. Optimal estimation results for $\mathrm{Li}_{2} \mathrm{O}$ and $\mathrm{Ta}_{2} \mathrm{O}_{5}$ grade occurred when using the OK method and when the fractal model is used. When image 5 is used and the discrete interval is divided into 10 pieces, the $\mathrm{Li}_{2} \mathrm{O}$ grade has the best M-I estimation result. When image 4 is used and the discrete interval is divided into 14 pieces, the $\mathrm{Ta}_{2} \mathrm{O}_{5}$ grade has the best estimation result.

\subsection{Estimation results analysis}

A comparison is presented of the estimation method characteristics of the IDW1, IDW2, OK, and M-I methods. Deviation analysis, trend analysis, and variogram analysis were performed on $\mathrm{Li}_{2} \mathrm{O}$ and $\mathrm{Ta}_{2} \mathrm{O}_{5}$ grades. Finally, the advantages of the M-I method were compared with IDW1, IDW2 and the OK methods.

\subsubsection{Deviation analysis}

The estimated deviation of the optimal estimated grade of porcelain clay was analyzed. The minimum deviation of $\mathrm{Li}_{2} \mathrm{O}$ esti-

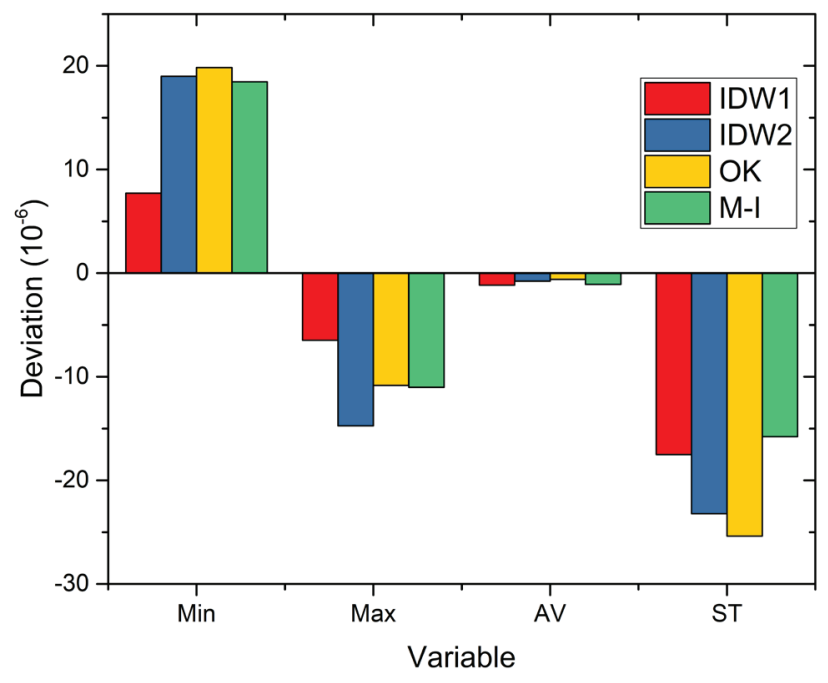

Fig. $14 \mathrm{Li}_{2} \mathrm{O}$ grade estimation deviation.

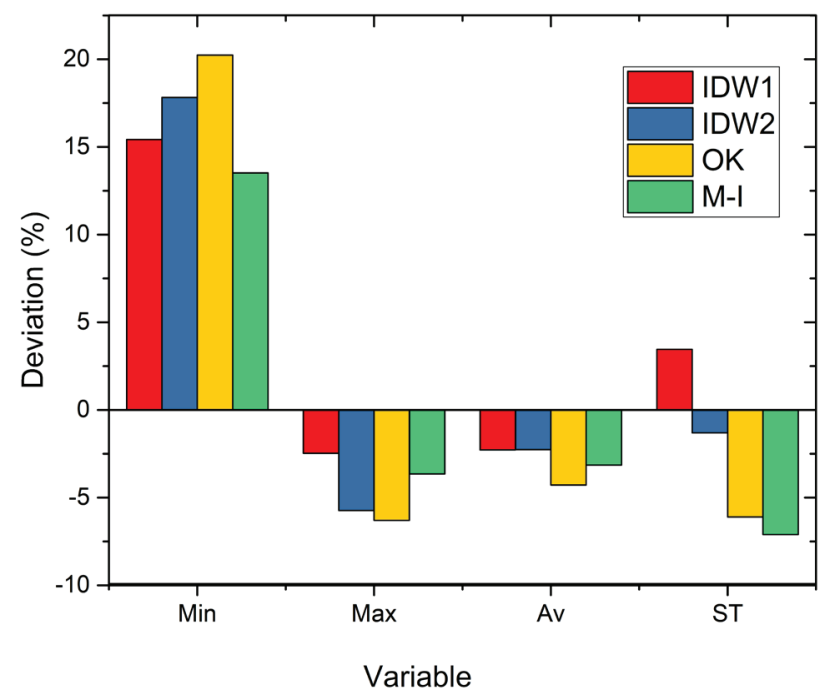

Figure 15. $\mathrm{Ta}_{2} \mathrm{O}_{5}$ grade estimation deviation.

mated grade ranges from $13.52 \%$ to $20.24 \%$ (Fig. 14). The maximum deviation ranges from $2.47 \%$ to $6.30 \%$. The $\mathrm{Li}_{2} \mathrm{O}$ grade estimation minimum deviation is significantly greater than the maximum deviation. Estimation results of the IDW1, IDW2, OK,

Table 7. Optimal estimation results of $\mathrm{Li}_{2} \mathrm{O}$ grade.

\begin{tabular}{|c|c|c|c|c|c|c|c|c|c|}
\hline Method & $\begin{array}{l}\text { Min } \\
(\%)\end{array}$ & $\begin{array}{r}\text { Max } \\
(\%)\end{array}$ & $\begin{array}{c}\text { Average } \\
(\%)\end{array}$ & Variance & $\begin{array}{l}\text { Standard } \\
\text { deviation }\end{array}$ & $\begin{array}{c}\text { Median } \\
(\%)\end{array}$ & Kurtosis & Skewness & $\begin{array}{l}\text { Coefficient } \\
\text { of variation }\end{array}$ \\
\hline IDW1 & 0.2704 & 0.8465 & 0.5000 & 0.0127 & 0.1129 & 0.5101 & -0.2713 & -0.3560 & 0.2257 \\
\hline OK & 0.2817 & 0.8133 & 0.4898 & 0.0105 & 0.1026 & 0.4972 & -0.2813 & -0.5665 & 0.2094 \\
\hline M-I & 0.2660 & 0.8362 & 0.4956 & 0.0103 & 0.1015 & 0.5194 & -0.1233 & -0.6617 & 0.2048 \\
\hline
\end{tabular}

Table 8. Optimal estimation results of $\mathrm{Ta}_{2} \mathrm{O}_{5}$ grade.

\begin{tabular}{|c|c|c|c|c|c|c|c|c|c|}
\hline Method & $\begin{array}{l}\text { Min } \\
\left(10^{-6}\right)\end{array}$ & $\begin{array}{l}\text { Max } \\
\left(10^{-6}\right)\end{array}$ & $\begin{array}{c}\text { Average } \\
\left(10^{-6}\right)\end{array}$ & Variance & $\begin{array}{l}\text { Standard } \\
\text { deviation }\end{array}$ & $\begin{array}{c}\text { Median } \\
\left(10^{-6}\right)\end{array}$ & Kurtosis & Skewness & $\begin{array}{l}\text { Coefficient } \\
\text { of variation }\end{array}$ \\
\hline IDW1 & 16.6269 & 92.9562 & 38.4829 & 44.4826 & 6.6695 & 38.8171 & -0.0167 & 5.6815 & 0.1733 \\
\hline IDW2 & 18.3676 & 84.7443 & 38.6357 & 38.5344 & 6.2076 & 38.7802 & -0.2967 & 3.4585 & 0.1607 \\
\hline OK & 18.4970 & 88.6346 & 38.6976 & 36.4862 & 6.0404 & 38.7437 & -0.2018 & 4.0988 & 0.1561 \\
\hline$M-I$ & 18.2870 & 88.4411 & 38.5101 & 44.2511 & 6.8176 & 36.4270 & 0.0257 & 2.5824 & 0.1770 \\
\hline
\end{tabular}




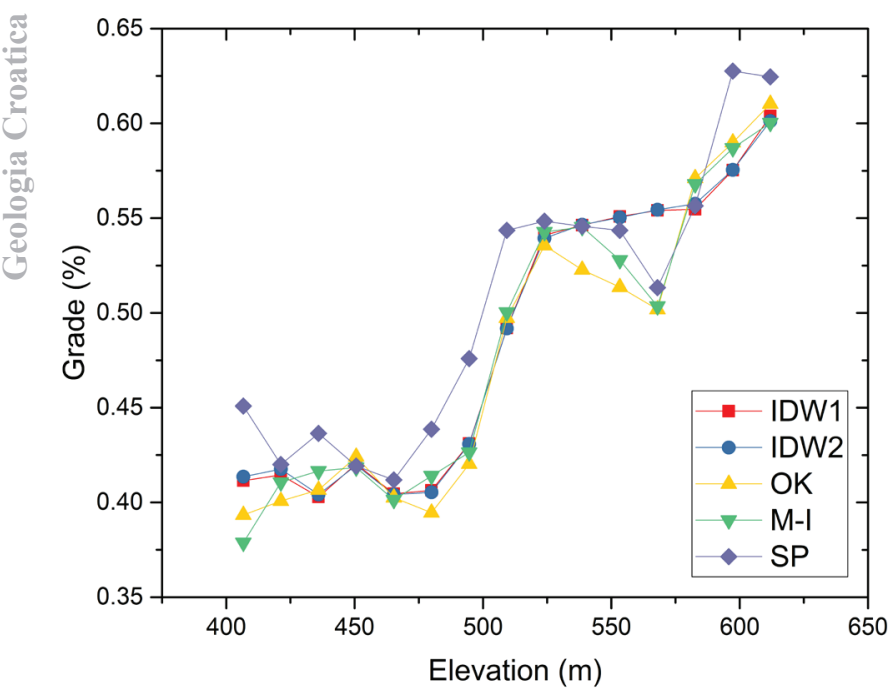

Figure 16. Trend analysis of $\mathrm{Li}_{2} \mathrm{O}$ grade.

and M-I methods are similar, indicating that the large minimum deviation is not due to a change in estimation method and the results of the M-I method are accurate. The average deviations of the IDW1, IDW2, OK, and M-I methods are $-2.28 \%, 2.26 \%$, $-4.28 \%$, and $-3.14 \%$, respectively. The deviation of the standard deviation of the estimation results of the 4 methods is small. The standard deviation of the IDW2 method is the smallest (1.31\%).

Figure 15. shows the estimated deviation of the $\mathrm{Ta}_{2} \mathrm{O}_{5}$ grade. The minimum deviation of the estimated grade of $\mathrm{Ta}_{2} \mathrm{O}_{5}$ ranges from $7.71 \%$ to $19.83 \%$. The maximum deviation ranges from $6.48 \%$ to $14.74 \%$. The average deviation ranges from $0.61 \%$ to $1.12 \%$. The $\mathrm{Ta}_{2} \mathrm{O}_{5}$ grades estimated by the 4 methods are extremely similar. Although samples used in the estimation are from the same exploration project, the deviations of the $\mathrm{Li}_{2} \mathrm{O}$ and $\mathrm{Ta}_{2} \mathrm{O}_{5}$ grades are different for the same estimation methods, in-
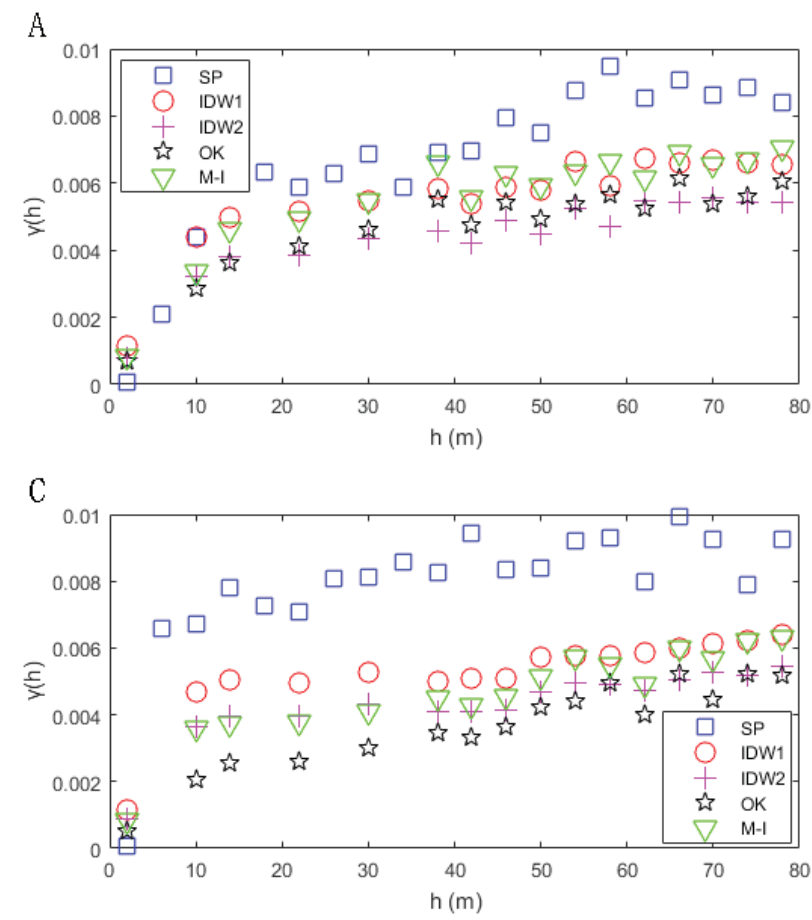

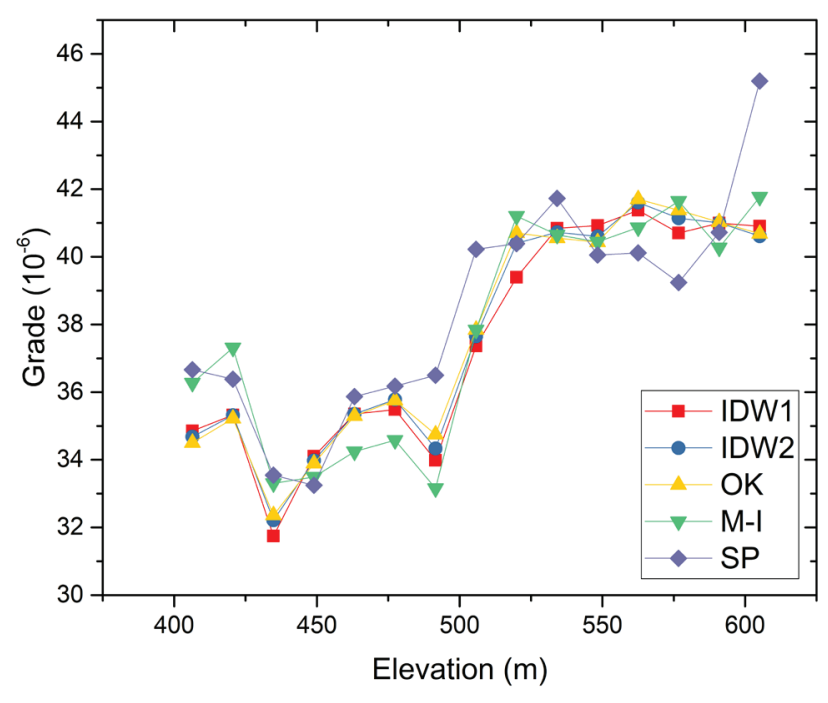

Figure 17. Trend analysis of $\mathrm{Ta}_{2} \mathrm{O}_{5}$ grade.

dicating that sample grade distribution has an obvious influence on the estimation results. In addition, the estimated deviations of the 4 methods are very similar for the same grade estimation. This further illustrates that the estimation results of the improved multipoint geostatistics (M-I) are reliable and accurate.

\subsubsection{Trend analysis}

Trend analysis was performed on the $\mathrm{Li}_{2} \mathrm{O}$ and $\mathrm{Ta}_{2} \mathrm{O}_{5}$ estimated grades for porcelain clay. Figure 16. shows the trend of the $\mathrm{Li}_{2} \mathrm{O}$ grade change with elevation. Overall, the estimated ore grade is lower than the actual ore grade. $\mathrm{The} \mathrm{Li}_{2} \mathrm{O}$ grade at the shallow (large) elevation of the ore body is higher than the deep (small elevation) grade. $\mathrm{The}_{\mathrm{Li}} \mathrm{O}$ grades estimated by the IDW1, IDW2, OK, and M-I methods have greater consistency with the elevation trends, and the estimated grades for the different methods are similar. Figure 17. shows the trend of the $\mathrm{Ta}_{2} \mathrm{O}_{5}$ grade with

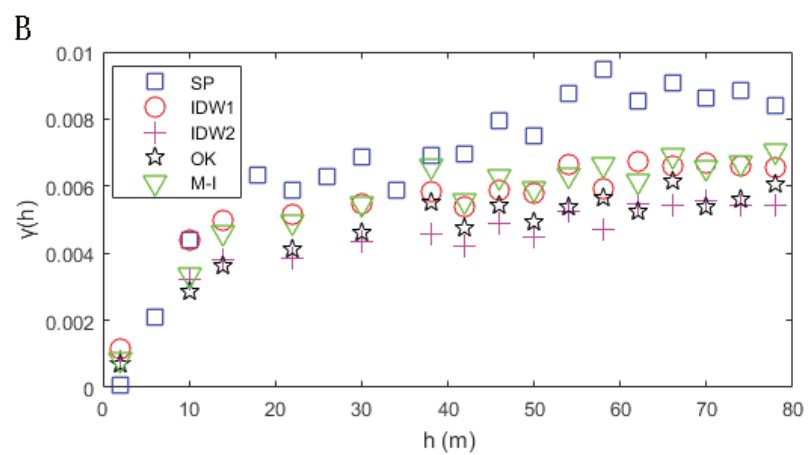


A

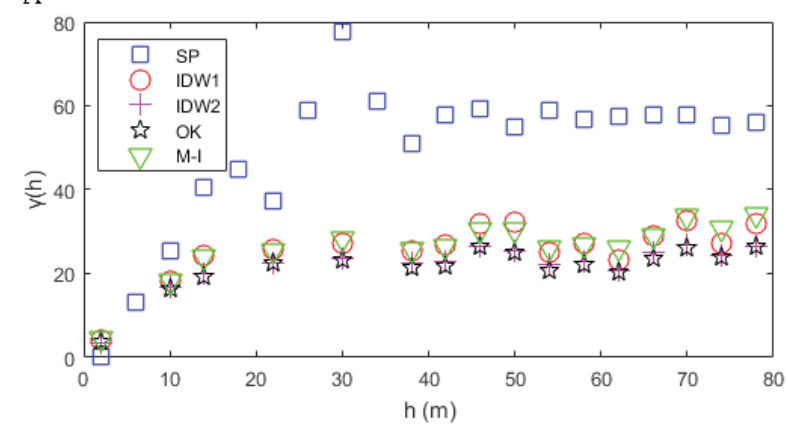

C

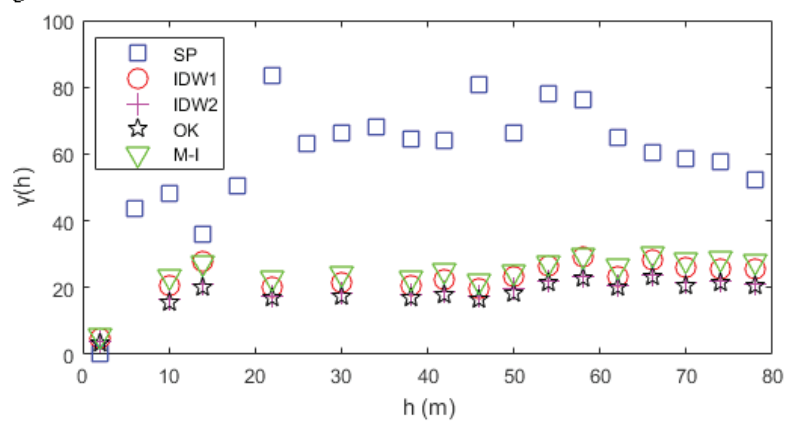

B

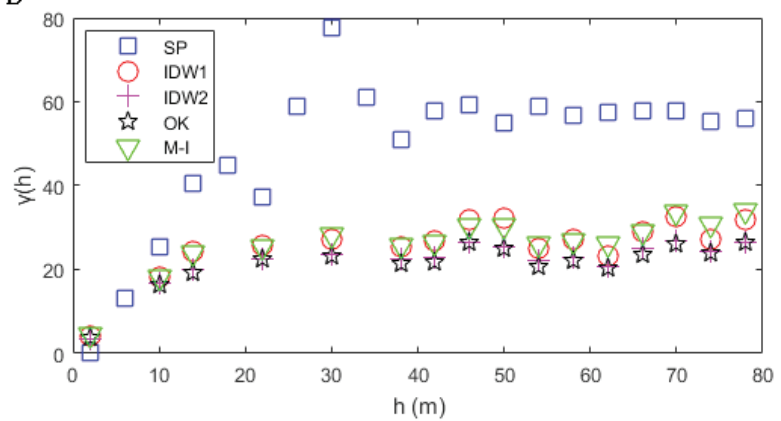

Figure 19. Variogram analysis of $\mathrm{Ta}_{2} \mathrm{O}_{5}$ grade. $\mathrm{A}, \mathrm{B}$, and $\mathrm{C}$ are the variograms of the estimated and sample grade in the $\mathrm{X}, \mathrm{Y}$, and $\mathrm{Z}$ directions, respectively.

elevation. $\mathrm{The} \mathrm{Ta}_{2} \mathrm{O}_{5}$ and $\mathrm{Li}_{2} \mathrm{O}$ estimation trends are similar. The $\mathrm{Li}_{2} \mathrm{O}$ and $\mathrm{Ta}_{2} \mathrm{O}_{5}$ grade is greater at higher elevation (shallow) than at lower elevation (deep).

\subsubsection{Variogram analysis}

The variograms of the estimated grade and sample grade of $\mathrm{Li}_{2} \mathrm{O}$ and $\mathrm{Ta}_{2} \mathrm{O}_{5}$ are shown in Figures 18. and 19. The IDW1 method used 3 samples in the estimation process. The IDW2 and OK methods used 5 samples. The number of samples included in the estimation using the IDW method in the M-I method is 4. The largest difference between the $\mathrm{Li}_{2} \mathrm{O}$ estimated grade and sample grade variograms is in the $\mathrm{X}$ and $\mathrm{Y}$ directions for the IDW2 method. The OK method has the second largest gap. The variogram based on the IDW1 method is closer to the sample grade than the M-I variogram. That is to say that the IDW1 variogram is closest to the sample grade in the $\mathrm{X}$ and $\mathrm{Y}$ directions. In the $\mathrm{Z}$ direction, the difference between the $\mathrm{Li}_{2} \mathrm{O} \mathrm{OK}$ variogram and the sample grade variogram is the largest. The second largest gap is in the IDW2 variogram. Similarly, the IDW1 $\mathrm{Li}_{2} \mathrm{O}$ grade estimated is closest to the sample grade, followed by M-I. The $\mathrm{Li}_{2} \mathrm{O}$ variograms indicate that the number of samples participating in the estimation has important effect on the estimated grade variogram.

Variograms of the estimated $\mathrm{Ta}_{2} \mathrm{O}_{5}$ grade differ greatly from the sample variogram (Fig. 19). The difference among the estimated grade variograms is small. The OK and IDW2 variograms are similar, and the IDW1 and M-I variograms are also similar. The IDW1 and M-I variograms are slightly more similar than the OK and IDW2 variograms. Overall, the variograms of the estimated grade are significantly lower than that of the samples. The IDW2 and OK estimated grades have a stronger smoothing effect. Although the $\mathrm{Li}_{2} \mathrm{O}$ and $\mathrm{Ta}_{2} \mathrm{O}_{5}$ samples are from the same exploration project, the gap between the estimated variograms and sample variograms is different, indicating that the sample grade distribution has an effect on the morphology of the variogram.
Comprehensive analysis of the $\mathrm{Li}_{2} \mathrm{O}$ and $\mathrm{Ta}_{2} \mathrm{O}_{5}$ grade variograms indicates that the greater the number of samples participating in the estimation, the larger the difference between the sample grade variogram and the estimated grade variogram will be. If the same number of samples participate in the estimation, the estimation result of the OK method has a higher smoothness than that of the IDW2 method. If the number of samples participating in the estimation increases, the variogram of the IDW estimated grade becomes smoother. The sample distribution significantly influences the estimated grade variogram. The estimated grade for the M-I method is similar to that of the IDW and $\mathrm{OK}$ methods, indicating that the ore grades estimated by the multi-point geostatistical method are reliable and accurate.

\section{DISCUSSION}

Valuation using the M-I method indicates that improving the training image resolution can improve the MPG valuation to some extent. However, increasing the training image resolution seriously affects the computational efficiency and does not completely solve the problem of matching between data events and data patterns. Matching efficiency between the data events and data patterns is an important factor affecting the accuracy of multi-point geostatistical estimation. In theory, increasing the number of discrete intervals can improve valuation accuracy, but it will reduce the matching rate between data events and data patterns, which affects valuation accuracy. The M-I method can overcome the issue of inaccurate low-frequency grade information in MPG estimation. The study produced the optimal results for different training images and discrete interval numbers when estimating using the M-I method.

This study evaluated the grades of $\mathrm{Li}_{2} \mathrm{O}$ and $\mathrm{Ta}_{2} \mathrm{O}_{5}$ in porcelain clay using an improved MPG method. Results were compared with results from the OK and IDW method, demonstrating the feasibility, reliability, and accuracy of the M-I method for ore grade estimation. The stability and accuracy of multi-point geo- 
statistical estimation indicates that the new training image construction method is feasible. Compared with the OK method, the use of training images instead of variograms improves the utilization efficiency of sampling information. In other words, informational relationships between more samples are utilized. The improved method is theoretically superior to variograms that only utilize the pattern of information between two samples.

This study used deviation, trend, and variogram analyses to analyze the improved MPG method estimation features from different angles. It proves that the new training images improved data event matching methods, and the uncertainty problem processing methods can meet the requirements of ore grade estimation. An accurate estimate of the $\mathrm{Li}_{2} \mathrm{O}$ and $\mathrm{Ta}_{2} \mathrm{O}_{5}$ ore grades was achieved.

\section{CONCLUSION}

(1) This study introduced MPG into the field of ore grade estimation, provides a new training construction method, and applies it to $\mathrm{Li}_{2} \mathrm{O}$ and $\mathrm{Ta}_{2} \mathrm{O}_{5}$ ore grade estimation in a porcelain clay deposit. A good estimation result is obtained using the M-I method.

(2) The matching of data events and data patterns was improved. A new matching method was used to account for the directionality of the data template. The inverse distance weighted method was used to compensate for the lack of MPG. The improvements enhance the reliability of MPG estimates.

(3) This study produced the optimal estimation results for $\mathrm{Li}_{2} \mathrm{O}$ and $\mathrm{Ta}_{2} \mathrm{O}_{5}$ when the IDW, OK, and M-I methods were used. The grade distribution pattern is the main factor affecting the minimum and maximum deviation. If more samples are included in the estimation, the estimation results of the IDW and OK methods will be smoother.

(4) Deviation, trend, and variogram analyses were used to study the estimated features of the inverse distance weighted, ordinary Kriging, and multi-point geostatistics. The reliability and accuracy of the M-I estimations is shown by comparing the estimations of the IDW and OK methods.

\section{ACKNOWLEDGEMENT}

The funding was provided by the China National Natural Science Foundation (NO. 71363040).

\section{REFERENCES}

ABDOLLAHIFARD, M.J. \& NASIRI, B. (2017): Exploiting transformation-domain sparsity for fast query in multiple-point geostatistics.- Computational Geosciences, 21/2, 1-11. doi: 10.1007/s10596-016-9612-1

BURC ARPAT, G. \& CAERS, J. (2007): Conditional Simulation with Patterns.- Math. Geol., 39/02, 177-202.

GAO, S.C., TIAN, M. \& SUN, Z. (2016): Multiple-point Geostatistics modeling factors analysis and optimization by using Markov Chain model.- Mathematics in Practice and Theory, 46/0, 202-211.
GARDET, C., RAVALEC, M.L. \& GLOAGUEN, E. (2016): Pattern-based conditional simulation with a raster path: a few techniques to make it more efficient.- Stoch. Env. Res. Risk. A., 30/2, 429-446. doi: 10.1007/s00477-015-1207-1

GEIGER, J., JAKAB, N., CSÖKMEI, B., HORVÁTH, Z. \& GELLÉRT, B. (2016): Statistical and geostatistical study of Rn and hydrocarbon components of a soil gas monitoring system: an application to surface hydrocarbon exploration.- Geologia Croatica, 69/2, 255-268. doi: 10.4154/gc.2016.21

HANSEN, T.M. \& LE, T.V. (2016): Bach T. MPSLIB: A C++ class for sequential simulation of multiple-point statistical models.- Soft. X., 5, 127-133.

HU, L. Y. \& CHUGUNOVA, T. (2008): Multiple-point geostatistics for modeling subsurface heterogeneity: A comprehensive review.- Water. Resour. Res., 44, 1-14. doi: 10.1029/2008WR006993

HUYSMANS, M., ORBAN, P. \& COCHET, E. (2014): Using Multiple-Point Geostatistics for Tracer Test Modeling in a Clay-Drape Environment with Spatially Variable Conductivity and Sorption Coefficient.- Math. Geosci., 46, 519-537. doi: 10.1007/s11004-013-9502-1

KUMARI, M. \& SINGH, C.K. (2018): GaRiRO: Gradient and residual integrated rank ordering of stations in rainfall monitoring network.- Earth. Sci. Inform., 11, 1-14. doi: $10.1007 / \mathrm{s} 12145-018-0332-\mathrm{Z}$

LI, Z.L., WANG, P. \& ZHANG, X.L. (2008): Improvement and application of inverse distance weighted method.- Met. Min., 02, 88-92.

LUO, H.M., YANG, P.J. \& WANG, C.J. (2015): Litho facies simulation based on multiple-point geostatistics multiple data joint constraints.- Oil Geophysical Prospecting, 50/01, 162-169+19.

NOVAK ZELENIKA, K., VIDAČEK, R., ILIJAŠ, T. \& PAVIĆ, P. (2017): Application of the deterministical and stochastical geostatistical methods in petrophysical modeling, case study upper Pannonian reservoir in Sava depression.- Geologia Croatica, 70/2, 105-114. doi: 10.4154/gc.2017.10

STRAUBHAAR, S., RENARD, P. \& MARIETHOZ, G. (2016): Conditioning Multiplepoint Statistics Simulations to Block Data.- Spatial Statistics, 16, 53-71. doi: 10.1016/j.spasta.2016.02.005

STREBELLE, S. (2001): Sequential simulation drawing structures from training images.- Palo Alto, PhD Thesis, Faculty of Science, Stanford University.

VRIES, L.M.D., CARRERA, J. \& FALIVENE, O. (2009): Application of Multiple Point Geostatistics to Non-stationary Images.- Math. Geosci., 41/1, 29. doi: 10.1007/ s11004-008-9188-y

WANG, G.W., FENG, Y. \& CARRANZA, M. (2016): Typomorphic characteristics of pyrite: Criteria for 3D exploration targeting in the Xishan gold deposit, China.- J. Goechem. Explor., 164, 136-163. doi: 10.1016/j.gexplo.2016.01.003

WU, T. \& FU, B. (2016): Application of the multiple-point method to geological modeling in the Sulige gasfield.- Geol. Prospect., 52/05, 985-991.

YANG, P.J. (2014): Geostatistics inversion from two-point to multiple-point.- Chin. J. Geophys. Progr., 29/05, 2293-2300.

YIN, Y.S., WU, S.H. \& ZHAI, R. (2008): The forecasting of fluvial facies reservoir distribution by using Simpat.- J. Southwest Petrol. Univ., 02, 19-22+184-185.

YIN, Y.S., WU, S.H. \& ZHANG, C. (2008): M. Multi-point geostatistical method based on reservoir skeleton.- Sci. China Ser. D., S2, 157-164.

YU, S.Y., LI, S.H. \& HE, Y.B. (2016): Multiple-point geostatistics algorithm bases on pattern scale-down cluster-- Acta. Petrol. Sinica, 37/11, 1403-1409.

ZHANG, T., BOMBARDE, S. \& STREBELLE, S. B. (2006): 3D porosity modeling of a carbonate reservoir using continuous multiple point statistics simulation.- SPE Journal, 11/3, 375-379. doi: 10.2118/96308-PA

ZHANG, T., DU, Y. \& HUSNG, T. (2015): A reconstruction method for spatial data using parallel SNESIM.- J. Comput. Dev., 52/06, 1431-1442.

ZUO, C., TENG, Q.Z. \& HE, X.H. (2016): A fast 3D reconstruction algorithm of multiple point statistics.- J. Sichuan Univ: Natl. Sci. Ed., 53/02, 337-346.

Author Contributions statement: Yu-Chen Song designed the experiment, Zhan-Ning Liu performed the experiment and wrote the paper, Xiao-Yan Yu processed the data and images, and Hai-Dong Meng revised the paper.

Competing interests statement: The authors declare that there are no competing interests between them, including financial and non-financial interests. 